\title{
The Role of Polar, Lamdba $(\Lambda)$-Shaped Building Units in Noncentrosymmetric Inorganic Structures
}

\author{
Martin D. Donakowski, ${ }^{\dagger \dagger}$ Romain Gautier, ${ }^{\dagger \dagger}$ Jeongho Yeon, ${ }^{\S}$ Donald T. Moore, "Juan C. Nino," \\ P. Shiv Halasyamani, ${ }^{\S}$ and Kenneth R. Poeppelmeier*, \\ ${ }^{\ddagger}$ Department of Chemistry, Northwestern University, 2145 Sheridan Road, Evanston, Illinois 60628-3113, United States \\ ${ }^{\S}$ Department of Chemistry, University of Houston, 136 Fleming Building, Houston, Texas 77204-5003, United States \\ "Department of Materials Science and Engineering, University of Florida, Gainesville, Florida 32611, United States
}

\section{Supporting Information}

\begin{abstract}
A methodology for the design of polar, inorganic structures is demonstrated here with the packing of lambda $(\Lambda)$-shaped basic building units (BBUs). Noncentrosymmetric (NCS) solids with interesting physical properties can be created with BBUs that lack an inversion center and are likely to pack into a polar configuration; previous methods to construct these solids have used NCS octahedra as BBUs. Using this methodology to synthesize NCS solids, one must increase the coordination of the NCS octahedra with maintenance of the noncentrosymmetry of the bulk. The first step in this progression from an NCS octahedron to an inorganic NCS solid is the formation of a bimetallic BBU. This step is exemplified with the compound $\mathrm{CuVOF}_{4}\left(\mathrm{H}_{2} \mathrm{O}\right)_{7}$ : this compound, presented here, crystallizes in an NCS structure with ordered, isolated $\left[\mathrm{Cu}\left(\mathrm{H}_{2} \mathrm{O}\right)_{5}\right]^{2+}$ cations and $\left[\operatorname{VOF}_{4}\left(\mathrm{H}_{2} \mathrm{O}\right)\right]^{2-}$ anions into $\Lambda$-shaped, bimetallic BBUs to form

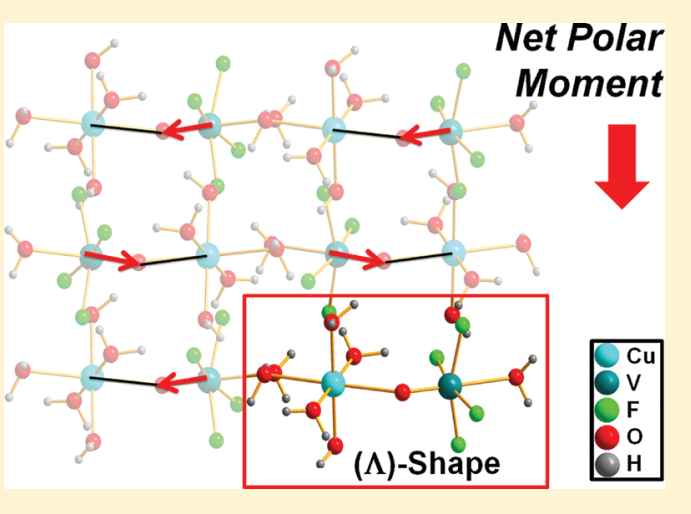
$\mathrm{CuVOF}_{4}\left(\mathrm{H}_{2} \mathrm{O}\right)_{6} \cdot \mathrm{H}_{2} \mathrm{O}$, owing to the Jahn-Teller distortion of $\mathrm{Cu}^{2+}$. Conversely, the centrosymmetric heterotypes with the same formula $\mathrm{MVOF}_{4}\left(\mathrm{H}_{2} \mathrm{O}\right)_{7}\left(\mathrm{M}^{\mathrm{II}}=\mathrm{Co}, \mathrm{Ni}\right.$, and $\left.\mathrm{Zn}\right)$ exhibit ordered, isolated $\left[\mathrm{VOF}_{4}\left(\mathrm{H}_{2} \mathrm{O}\right)\right]^{2-}$ and $\left[\mathrm{M}\left(\mathrm{H}_{2} \mathrm{O}\right)_{6}\right]^{2+}$ ionic species in a hydrogen bond network. $\mathrm{CuVOF}_{4}\left(\mathrm{H}_{2} \mathrm{O}\right)_{7}$ exhibits a net polar moment while the heterotypes do not; this demonstrates that $\Lambda$-shaped BBUs give a greater probability for and, in this case, lead to NCS structures.
\end{abstract}

\section{INTRODUCTION}

The relationship between noncentrosymmetric (NCS) crystals and pyroelectric, ferroelectric, piezoelectric, and/or second harmonic generation (SHG) properties has been welldeveloped, ${ }^{1-3}$ but NCS crystal design remains difficult. ${ }^{4-11}$ Polar, NCS crystal synthesis is challenging because multiple effects, such as steric or dipole-dipole interactions, typically combine to form nonpolar, centrosymmetric (CS) structures. Therefore, it is necessary for the inorganic chemistry community to develop new strategies to create NCS materials and obtain high nonlinear optical (NLO) responses. ${ }^{12,13}$

NCS crystal engineering in inorganic chemistry can be summarized as (i) the design of specific basic building units (BBUs) and (ii) control of the packing and polar directionality of these BBUs. Chen's anionic group theory established that distorted anionic groups could serve as NCS BBUs; accordingly, attention has been paid toward anionic polyhedra, particularly borates, as BBUs to construct NCS materials. ${ }^{6,9,10,14-23}$ It is difficult to control the crystallization of anionic groups into an NCS structure; however, our understanding of oxide-fluoride ligand ordering and structure-directing properties has allowed a guided synthesis for the formation of different BBUs. ${ }^{19,23,24}$ We have observed that early transition metal complexes (ETMCs) have cis and trans directing properties owing to different nucleophilicities of the ligands of the ETMCs. From these properties, we have incorporated ETMCs directly into different bond networks with inherent noncentrosymmetry. ${ }^{13,20,23}$

Adil et al. classified organometallic fluorides as $0 \mathrm{D}$ to $3 \mathrm{D}$; finite OD BBUs are the simplest structures and are subclassified as dimers, trimers, ..., to heptamers. ${ }^{25}$ Previous inorganic compounds that contain OD ETMC BBUs include $\left[\mathrm{Ni}\left(\mathrm{H}_{2} \mathrm{O}\right)_{6}\right]$ $\left[\mathrm{MF}_{6}\right][\mathrm{M}(\mathrm{IV})=\mathrm{Ti}, \mathrm{Zr}, \mathrm{Hf}]$ and organically templated $(\mathrm{RH})_{2}$ [ $\left.\mathrm{TiF}_{6}\right](\mathrm{R}=$ pyridine; picoline; 2,6-lutidine; 2,4,6-collidine $)$ and $[2,6$-lutidinium $]\left[\mathrm{TiF}_{5}\left(\mathrm{H}_{2} \mathrm{O}\right)\right]$, wherein the BBUs are connected only through hydrogen bonds. ${ }^{26,27}$ Stephens et al. synthesized $\left[\mathrm{C}_{2} \mathrm{~N}_{2} \mathrm{H}_{10}\right]\left[\operatorname{VOF}_{4}\left(\mathrm{H}_{2} \mathrm{O}\right)\right]$, in which the organic ligand templates the OD BBUs into polar alignment. ${ }^{10}$ The polar arrangement of the $\left[\operatorname{VOF}_{4}\left(\mathrm{H}_{2} \mathrm{O}\right)\right]^{2-}$ anions within this compound is not only attributable to the polar nature of the anion but also owing to the bond network (specifically, the hydrogen bond network). We see similar effects in $\mathrm{NCS} \mathrm{CuVOF}_{4}\left(\mathrm{H}_{2} \mathrm{O}\right)_{7}$, presented here, in that hydrogen bonds orient the polar moments in an additive manner.

Another possible method to create NCS materials is to extend the 0D polar octahedra of ETMCs to polymeric structures with

Received: November 22, 2011

Published: February 15, 2012 
metal fluoride BBUs to potentially create $1 \mathrm{D}$ to $3 \mathrm{D}$ units. $^{28}$ This "bottom up" approach would generate a 3D NCS structure from a $\mathrm{OD}$ BBU by progressively increasing the coordination of polar BBUs.

Kunz and Brown have reported four factors for the configuration of distorted ETMCs: (i) bond network, (ii) lattice stresses, (iii) cation-cation repulsions, and (iv) electronic effects; factors (i) and (iii) can influence the directionality of distortions within BBUs. ${ }^{29}$ The directions of the distortions create a net polarity in the bulk material. To maximize the NLO response of a material, the distortions within a bond network should be aligned in a parallel manner.

Simultaneous to the inorganic solid-state chemistry efforts to orient NCS BBUs in a polar, additive manner, organic chemistry has tailored organic molecules to form $\Lambda$-shaped molecules that pack in NCS configurations to create a second harmonic generation (SHG) response. ${ }^{30-33}$ Yamamoto et al. reported that polar $\Lambda$-shaped organic molecules are more likely to lead to NCS materials because of predictable crystal packing that aligns the $\Lambda$-shaped molecules (or BBUs). ${ }^{30}$ This $\Lambda$ shape is similar to BBUs hypothesized by Chen to synthesize NCS materials without transition metal elements, but we demonstrate here that $\Lambda$-shaped-BBUs can be synthesized with early transition metals, such as those that are prone to strong electronic distortions. $^{34,35}$

The NCS compound $\mathrm{CuVOF}_{4}\left(\mathrm{H}_{2} \mathrm{O}\right)_{7}$ combines these methodologies to use polar ETMCs in $\Lambda$-shaped BBUs. Additionally, hydrothermal chemistry allowed for the isolation of heterotypes of the same formula $\operatorname{MVOF}_{4}\left(\mathrm{H}_{2} \mathrm{O}\right)_{7}$ $\left(\mathrm{M}^{\mathrm{II}}=\mathrm{Co}, \mathrm{Ni}, \mathrm{Zn}\right)$ that conversely exhibit $\mathrm{CS}$ structures. The compounds $\mathrm{CuVOF}_{4}\left(\mathrm{H}_{2} \mathrm{O}\right)_{7}$ and $\mathrm{MVOF}_{4}\left(\mathrm{H}_{2} \mathrm{O}\right)_{7}\left(\mathrm{M}^{\mathrm{II}}=\right.$ $\mathrm{Co}, \mathrm{Ni}, \mathrm{Zn}$ ) are paramagnetic and show vanadyl bond strengths associated with primary, pseudo Jahn-Teller (PJT) distortions and secondary network distortions; the compound $\mathrm{CuVOF}_{4}\left(\mathrm{H}_{2} \mathrm{O}\right)_{7}$ has piezoelectric and SHG properties. We argue that polar, $(\Lambda)$-shaped BBUs will be likely to crystallize in NCS environments.

\section{EXPERIMENTAL METHODS}

Caution. Hydrofluoric acid is toxic and corrosive! It must be handled with extreme caution and the appropriate protective gear and training. ${ }^{36-38}$

Materials. Copper oxide (99.99+\%), nickel oxide (99.99\%), and hydrofluoric acid (49\% $\mathrm{HF}_{\mathrm{aq}}$ by weight) were used as received from Sigma-Aldrich. Cobalt carbonate ( $99.5 \%$ metals basis), zinc oxide (99.99\%), and vanadium dioxide (99.9\% trace metals basis) were used as received from Alfa-Aesar. Deionized water was used as backfill in the pressure vessels.

Single-Crystal MVOF $_{4}\left(\mathrm{H}_{2} \mathrm{O}\right)_{7}$ Synthesis and Isolation. With the exception of $\mathrm{CoVOF}_{4}\left(\mathrm{H}_{2} \mathrm{O}\right)_{7}$, the compounds were synthesized by the reaction of $4.07 \mathrm{mmol}$ of $\mathrm{MO}\left[\mathrm{M}^{\mathrm{II}}=\mathrm{Ni}, \mathrm{Cu}, \mathrm{Zn}\right]$ with $4.07 \mathrm{mmol}$ of $\mathrm{VO}_{2}(0.338 \mathrm{~g})$ and $0.60 \mathrm{~mL}$ of $49 \% \mathrm{HF}_{\mathrm{aq}}$ in a Teflon [fluoro(ethylenepropylene), FEP] pouch made as described previously. ${ }^{39}$ $\mathrm{CoVOF}_{4}\left(\mathrm{H}_{2} \mathrm{O}\right)_{7}$ was synthesized using the same process with an equimolar amount of $\mathrm{CoCO}_{3}$ in place of $\mathrm{MO}$ and $2.00 \mathrm{~mL}$ of $49 \%$ $\mathrm{HF}_{\mathrm{aq}}$. The slow addition of $\mathrm{HF}$ to the $\mathrm{CoCO}_{3}$ mixture was followed by a release of $\mathrm{CO}_{2}(\mathrm{~g})$. The evolution of $\mathrm{CO}_{2}(\mathrm{~g})$ was allowed to complete before the pouch was sealed. Each pouch was placed, alone, in a $125 \mathrm{~mL}$, Teflon-lined Parr acid-digestion vessel with $40 \mathrm{~mL}$ of deionized water, heated at $150{ }^{\circ} \mathrm{C}$ for $24 \mathrm{~h}$, cooled to $25^{\circ} \mathrm{C}$ at a $0.1{ }^{\circ} \mathrm{C} / \mathrm{min}$ rate, and left undisturbed for $48 \mathrm{~h}$ to allow crystallization. Reactions were performed at temperatures between 75 and $250{ }^{\circ} \mathrm{C}$ with no noticeable difference in the resulting products. After crystallization, the pouches were then opened and crystals of $\mathrm{CuVOF}_{4}\left(\mathrm{H}_{2} \mathrm{O}\right)_{7}$ or
$\mathrm{MVOF}_{4}\left(\mathrm{H}_{2} \mathrm{O}\right)_{7}\left(\mathrm{M}^{\mathrm{II}}=\mathrm{Co}, \mathrm{Ni}, \mathrm{Zn}\right)$ and $\mathrm{AF}_{2} \cdot\left(\mathrm{H}_{2} \mathrm{O}\right)_{4}(\mathrm{~A}(\mathrm{II})=\mathrm{Co}, \mathrm{Ni}$, $\mathrm{Cu}, \mathrm{Zn})$ were recovered by vacuum filtration in air. Modification of the relative amounts of $\mathrm{HF}_{\mathrm{aq}}, \mathrm{MO}$, and $\mathrm{VO}_{2}$ did not produce other compounds, but increased ratios of $\mathrm{MO}: \mathrm{VO}_{2}$ led to an increased amount of $\mathrm{AF}_{2} \cdot\left(\mathrm{H}_{2} \mathrm{O}\right)_{4}$ to $\mathrm{MVOF}_{4}\left(\mathrm{H}_{2} \mathrm{O}\right)_{7}$. The $\mathrm{CoVOF}_{4}\left(\mathrm{H}_{2} \mathrm{O}\right)_{7}$, compound $\mathbf{1}$, consisted of dark green crystals $(0.3959 \mathrm{~g}, 1.207 \mathrm{mmol}, 29.6 \%$ yield based on $\left.\mathrm{VO}_{2}\right)$. $\mathrm{NiVOF}_{4}\left(\mathrm{H}_{2} \mathrm{O}\right)_{7}$, compound 2, consisted of green crystals $\left(0.9124 \mathrm{~g}, 2.784 \mathrm{mmol}, 83.0 \%\right.$ yield based on $\left.\mathrm{VO}_{2}\right)$. $\mathrm{CuVOF}_{4}\left(\mathrm{H}_{2} \mathrm{O}\right)_{7}$, compound 3, consisted of azure crystals $(0.8524 \mathrm{~g}$, $2.564 \mathrm{mmol}, 63.0 \%$ yield based on $\left.\mathrm{VO}_{2}\right) . \mathrm{ZnVOF}_{4}\left(\mathrm{H}_{2} \mathrm{O}\right)_{7}$, compound 4, consisted of azure crystals $(0.2768 \mathrm{~g}, 0.8278 \mathrm{mmol}, 20.2 \%$ yield based on $\mathrm{VO}_{2}$ ).

After the hydrothermal synthesis, with the exception of 3 , the pouches contained crystalline 1,2 , and $4, \mathrm{AF}_{2} \cdot\left(\mathrm{H}_{2} \mathrm{O}\right)_{4}$, and clear, colored solutions that further crystallized over a period of $48 \mathrm{~h}$ while the pouches were still sealed; neither HF nor water was removed from the system. The synthesis of 3 resulted in a clear, blue solution with no observable crystals of $\mathrm{CuVOF}_{4}\left(\mathrm{H}_{2} \mathrm{O}\right)_{7}$ nor fluoride hydrate side product. We speculate the different times for crystallization arise from different reaction mechanisms, wherein compound 3 requires a long time for the reaction of $\left[\mathrm{Cu}\left(\mathrm{H}_{2} \mathrm{O}\right)_{6}\right]^{2+}$ and $\left[\mathrm{VOF}_{4}\left(\mathrm{H}_{2} \mathrm{O}\right)\right]^{2-}$ ions to produce $\mathrm{CuVOF}_{4}\left(\mathrm{H}_{2} \mathrm{O}\right)_{6} \cdot \mathrm{H}_{2} \mathrm{O}$

After $48 \mathrm{~h}$ at room temperature, $\mathrm{CuVOF}_{4}\left(\mathrm{H}_{2} \mathrm{O}\right)_{7}$ crystallized from this solution in the sealed container. Large crystals (up to $\sim 1 \mathrm{~mm}$ on each side) of the compounds were easily separated from the fluoride hydrate side-products with tweezers. Powder XRD was used to confirm the compounds' purities (see Supporting Information, Figure S4). The compounds were initially synthesized in $0.60 \mathrm{~mL}$ of $\mathrm{HF}_{\mathrm{aq}}$ with equimolar amounts of $\mathrm{CuO}$ and $\mathrm{V}_{2} \mathrm{O}_{5}$ in place of $\mathrm{VO}_{2}$ as a vanadium source with $0.12 \mathrm{~mL}$ of hydrochloric acid as a reducing agent. Heated hydrochloric acid is a known reducing agent for $\mathrm{V}^{\mathrm{V}}$ oxide compounds. ${ }^{40,41}$ There were no noticeable differences in yield or purity when using $\mathrm{V}_{2} \mathrm{O}_{5}$ or $\mathrm{VO}_{2}$, but reactions with $\mathrm{V}^{\mathrm{IV}}$ precursors are reported herein for simplicity. The elemental content of each pure compound was observed qualitatively with EDX spectroscopy (see Supporting Information, Figure S5), and the metallic content was confirmed quantitatively with ICP-AES (see Supporting Information, Table S1).

Crystallographic Determination. Single crystal XRD data were obtained at $100 \mathrm{~K}$ with a Bruker Kappa APEX 2 CCD diffractometer with monochromated Mo K $\alpha$ radiation $(\lambda=0.71073 \AA)$. The crystalto-detector distance was $60 \mathrm{~mm}$. The data were integrated with the SAINT-V7.23A program. ${ }^{42}$ Absorption (numerical or multiscan) corrections were applied to the data in the program XPREP. ${ }^{43}$ The structures were determined by direct methods with Fourier difference syntheses with SIR97 or XS and then refined with SHELXL-97 within the WinGX suite. ${ }^{44-46}$ Additional symmetry elements were checked with the computer program PLATON; for compounds 1, 2, and 4 (the CS heterotypes), the software suggested reducing the size of the unitcell with maintenance of the $P \overline{1}$ space group. ${ }^{47}$ Implementation of the reduced unit-cell resulted in unacceptable fitness parameters, owing to incorrect vanadium environments generated (see Supporting Information, Figure S8 and Table S3). No appropriate, additional symmetry was found for compounds 1-4.

The flack parameter was determined in the WinGX suite, with use of SHELXL, to be $0.021(2) .{ }^{45,46}$ The absolute structure of compound 3 was confirmed with anomalous dispersion effects in the data. The analysis was performed in PLATON by use of Bayesian statistics to give values of P2(true), P3(true), P3(false), P3(rac-twin), and Hooft y as $1.000,1.000,0.0,0.0$, and 0.013 (2), respectively, based on 1295 of 1295 Bijvoet pairs. ${ }^{47,48}$ These results indicate that the crystal of compound 3 is not twinned and the absolute configuration of the NCS structure was correctly determined.

FTIR Measurements. The FT-IR spectra for compounds 1-4 were collected on a Bruker 37 Tensor FTIR equipped with an ATR germanium cell attachment. A total of 256 scans were recorded at $2 \mathrm{~cm}^{-1}$ resolution and averaged, and a background spectrum was subtracted. Values of $\mathrm{V}=\mathrm{O}$ symmetric and asymmetric stretching frequencies were determined by fits to two Gaussian functions. 
Magnetic Susceptibility. The magnetic susceptibility $(\chi)$ of compounds 1-4 was measured as a function of temperature from 5 to $300 \mathrm{~K}$ under a field of 1000 Oersted. The measurements were performed between 5 and $300 \mathrm{~K}$ in $1 \mathrm{~K}$ intervals with a Quantum Design MPMS superconducting quantum interference device (SQUID). The measurements were corrected for diamagnetic contributions $\left(\chi_{\text {diag }}=\right.$ $-139.4 \mathrm{emu} / \mathrm{mol})^{49}$

Impedance Measurements. Impedance measurements were performed to determine if compound 3 exhibited piezoelectric resonance. Single crystals of compound 3 were cleaved and polished until two surfaces were flat and parallel. The surfaces were masked with tape. Silver paste was then applied and allowed to dry. The crystal for measurement 1 had dimensions of $2.66 \mathrm{~mm} \times 2.58 \mathrm{~mm} \times 0.7 \mathrm{~mm}$, and the crystal for measurement 2 had dimensions of $2.88 \mathrm{~mm} \times 2.20 \mathrm{~mm} \times$ $0.6 \mathrm{~mm}$. The $f_{p}$ and $f_{s}$ peak positions of the first most intense resonance peak were determined using the find peak tool in Origin 8 . The impedance and admittance spectra were collected using an Agilent Precision Impedance Analyzer (4294A). A total of 25 sweeps containing 500 points over the desired frequency range were averaged and recorded. The effective coupling factor $\left(K_{\text {eff }}\right)$ was calculated because of the crystal's irregular dimensions with eq 1 , where $f_{p}$ is the maximum of the impedanceand $f_{s}$ is the minimum of the impedance spectrum. ${ }^{50}$

$$
K_{\mathrm{eff}}=\sqrt{\frac{f_{p}^{2}-f_{s}^{2}}{f_{p}^{2}}}
$$

Second Harmonic Generation Measurements. Powder SHG measurements were carried out on compound 3 with the Kurtz-Perry method. ${ }^{51,52}$ Since the SHG efficiency of powders depends on particle size, the compound was ground and sieved into particle-size ranges between 20 and $125 \mu \mathrm{m}$. Approximately $100 \mathrm{mg}$ of each size range of $\mathrm{CuVOF}_{4}\left(\mathrm{H}_{2} \mathrm{O}\right)_{7}$ particles was pressed into a pellet and then irradiated with a pulsed infrared beam $(100 \mathrm{~ns}, 15 \mathrm{~mJ}, 10 \mathrm{~Hz})$ produced by a Q-switched Nd:YAG laser of wavelength $1064 \mathrm{~nm}$. The SHG radiation (532 $\mathrm{nm}$ green light) was collected in reflection and detected by a photomultiplier tube. A $532 \mathrm{~nm}$ narrow band-pass interference filter was used to detect only the SHG-produced light. The SHG response of particles between 45 and $63 \mu \mathrm{m}$ was compared with particles of the same range of $\alpha-\mathrm{SiO}_{2}$.

\section{RESULTS}

Structural Descriptions. Centrosymmetric Compounds 1, 2, and 4 Contain Isolated Cations and Anions. Compounds 1, 2, and 4 have distorted vanadyl complexes (VCs) but crystallize in the centrosymmetric space group $P \overline{1}$ and have no uncoordinated water molecules within the lattice (see Figure 1a). The structures exhibit a structure similar to $\mathrm{CsCl}$ wherein each ion has eight nearest neighbors. No higher symmetry space groups could be found for the unit cells. The crystallographic parameters are shown in Table 1. To further confirm the structures, BVS calculations were performed (see Table 2) as well as EDX spectroscopy and ICP elemental analyses to confirm the elemental content (see Supporting Information, Figure S5 and Table S1) ${ }^{53-56}$ For the BVS calculations, values from Brese and O'Keefe were used for the metallic elements and values from Adams et al. were used for hydrogen-atom contributions to BVS. Each metallic ion occurs as an isolated octahedron with ordered ligands: $\left[\mathrm{M}\left(\mathrm{H}_{2} \mathrm{O}\right)_{6}\right]^{2+}$ and $\left[\operatorname{VOF}_{4}\left(\mathrm{H}_{2} \mathrm{O}\right)\right]^{2-}\left(\mathrm{M}^{\mathrm{II}}=\mathrm{Co}, \mathrm{Ni}\right.$, and $\left.\mathrm{Zn}\right)$. The late-transition metal complexes (LTMCs) are on inversion centers and/or corners of the unit cell. Each LTMC exists as an octahedron with three crystallographically equivalent water molecules. Bond distances of the VCs and their ligands are listed in the Supporting Information. Each VC has 14 hydrogen bonds with another LTMC and other VCs. Hydrogen bonds can be considered over various distances between hydrogen atoms and acceptors, distances between donors and acceptors, and bond angles of the donor-hydrogen-acceptor species. For this paper, the definition of "moderate and strong" hydrogen bonds is used as described by Jeffrey. ${ }^{57}$ Hydrogen atoms could be located in the Fourier syntheses during crystal structure refinement, consistent with hydrogen atom placement in moderately strong bonds within the structures.

Figures 2 and 3 show that the CS heterotypes hydrogen bond networks form chains of distorted VCs; the chains align in an antiparallel manner. The antiparallel configuration cancels the net polar moments of the VCs to form a CS structure. This CS structure is a result of two factors: (I) the VCs are OD complexes within a crystal structure and have many degrees of rotational freedom, and (II) the orientation of the VCs is determined by the strong dipole moments that are able to orient and cancel out within the unit cell to optimize the electrostatic energy of the unit cell. The VCs have no shared ligands with other octahedra. The LTMCs, shown in Figure 1b, are necessary to balance the anionic charge of the VCs and form the hydrogen bond network to stabilize the crystal structures. Numerous hydrogen bonds are formed to the VCs and LTMCs; these bonds are shown in the Supporting Information, Figures S9-S13. Relevant hydrogen-bond geometry parameters for compounds 1, 2, and $\mathbf{4}$ are given in the Supporting Information, Tables S7, S11, and S19, respectively. The cations and anions form a distorted $\mathrm{CsCl}$ three-dimensional configuration.

Similar structures such as $\left[\mathrm{Ni}\left(\mathrm{H}_{2} \mathrm{O}\right)_{6}\right]\left[\mathrm{MF}_{6}\right](\mathrm{M}(\mathrm{IV})=$ $\mathrm{Ti}, \mathrm{Zr}, \mathrm{Hf}$ ) have been observed and compared to isostructural compounds $\left[\mathrm{M}^{\mathrm{II}}\left(\mathrm{H}_{2} \mathrm{O}\right)_{6}\right]\left[\mathrm{M}^{\mathrm{IV}} \mathrm{F}_{6}\right]\left(\mathrm{M}^{\mathrm{II}}=\mathrm{Mg}, \mathrm{Mn}, \mathrm{Fe}, \mathrm{Co}, \mathrm{Ni}\right.$, or $\mathrm{Zn}$ and $\mathrm{M}^{\mathrm{IV}}=\mathrm{Si}, \mathrm{Ge}, \mathrm{Sn}, \mathrm{Ti}$, or $\left.\mathrm{Zn}\right) \cdot{ }^{26,58-60}$ To our knowledge, $\left[\mathrm{Cu}^{\mathrm{II}}\left(\mathrm{H}_{2} \mathrm{O}\right)_{6}\right]\left[\mathrm{M}^{\mathrm{IV}} \mathrm{F}_{6}\right]$ is notably absent from this series. These group IV elemental compounds provide an interesting comparison to compounds $\mathbf{1}, \mathbf{2}$, and $\mathbf{4}$. The group IV metals do not present pseudo-Jahn-Teller (PJT) distortions, and the structures exhibit trigonal symmetry. The triclinic symmetries of compounds $\mathbf{1}, \mathbf{2}$, and $\mathbf{4}$ are therefore an indirect result of the VC's PJT distortion that places the LTMCs into positions and configurations that can only be described by a triclinic symmetry. We attempted syntheses of both $\left[\mathrm{Cu}\left(\mathrm{H}_{2} \mathrm{O}\right)_{6}\right]\left[\mathrm{MF}_{6}\right]$ and $\mathrm{Cu}\left(\mathrm{H}_{2} \mathrm{O}\right)_{5}\left[\left(\mathrm{MOF}_{4}\right)_{2} \mathrm{O}\right]$ $(\mathrm{M}(\mathrm{IV})=\mathrm{Ti}, \mathrm{Zr}, \mathrm{Hf})$ but were unsuccessful, possibly owing to the instability of $\left[\mathrm{MOF}_{4}\left(\mathrm{H}_{2} \mathrm{O}\right)\right]^{2-}(\mathrm{M}(\mathrm{IV})=\mathrm{Ti}, \mathrm{Zr}$, Hf $)$, the inability for a first order Jahn-Teller (FOJT) distorted $\left[\mathrm{Cu}\left(\mathrm{H}_{2} \mathrm{O}\right)_{6}\right]^{2+}$ to exist in the hydrogen-bond network, and/ or the high enthalpy of formation for $\mathrm{CuF}_{2}{ }^{61}$

$\Lambda$-Shaped BBUs Are Present in Compound 3. Compound 3 crystallizes in the NCS space group Pna2 ${ }_{1}$; relevant crystallographic parameters are shown in Table 1. The NCS property was confirmed by SHG and piezoelectric measurements (see Supporting Information, Figures S1 and S2). To confirm the identity of the oxide and fluoride ligands, BVS calculations were performed (see Table 2) as well as EDX spectroscopy and ICP elemental analyses to confirm the elemental content (see Supporting Information, Table S1 and Figure S5)..$^{53-56}$ The crystal structure exists as a molecular crystal with neutral $\Lambda$ shaped BBUs bonded solely to the extended network with hydrogen bonds. Figure $1 \mathrm{~b}$ shows the crystal structure composed of $\mathrm{CuVOF}_{4}\left(\mathrm{H}_{2} \mathrm{O}\right)_{6}$ polar BBUs connected by inter-BBU hydrogen bonds. Each $\mathrm{BBU}$ contains oxygen-bridged [Cu$\left.\left(\mathrm{H}_{2} \mathrm{O}\right)_{5}\right]^{2+}$ and $\left[\left(\mathrm{VOF}_{4}\right) \mathrm{H}_{2} \mathrm{O}\right]^{2-}$ octahedra that are distorted by FOJT and PJT distortions, respectively. ${ }^{34}$ The vanadyl bond of $\left[\mathrm{VOF}_{4}\left(\mathrm{H}_{2} \mathrm{O}\right)\right]^{2-}$ exhibits a distortion from electronic and 


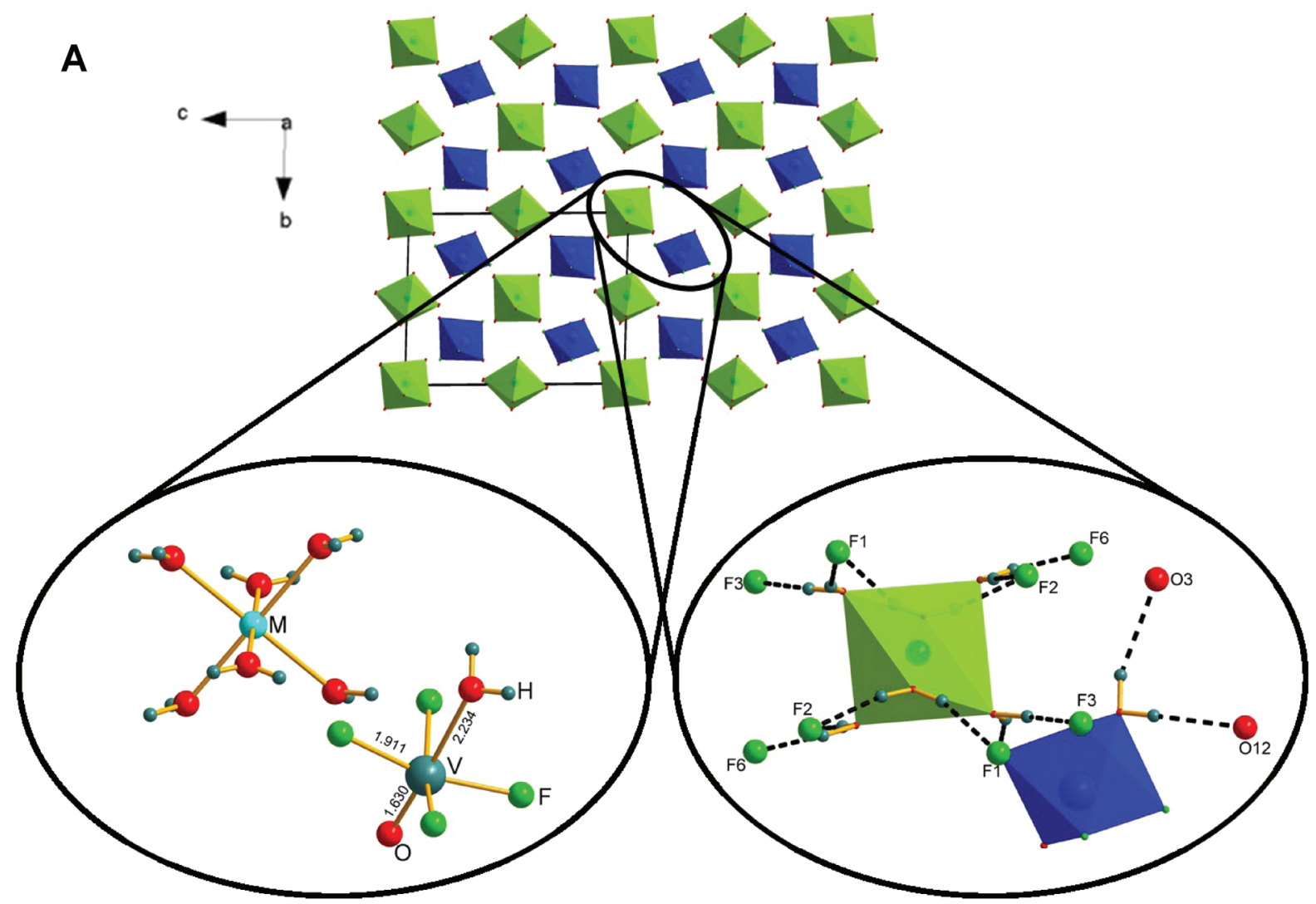

B
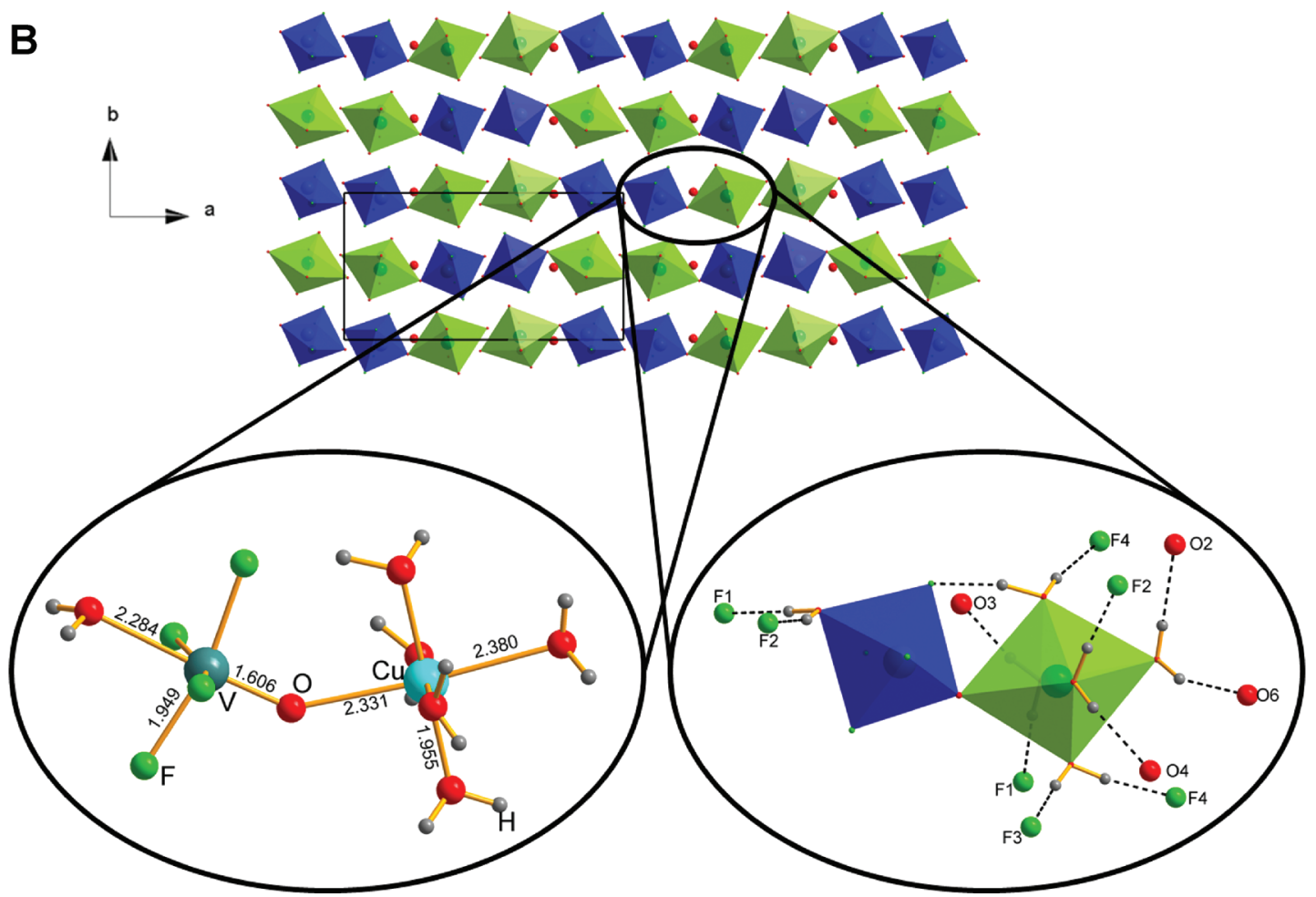

Figure 1. (A) Representation of $\left[\mathrm{M}\left(\mathrm{H}_{2} \mathrm{O}\right)_{6}\right]^{2+}$ and $\left[\mathrm{VOF}_{4}\left(\mathrm{H}_{2} \mathrm{O}\right)\right]^{2-}$ ions of the CS heterotypes 1, 2, and 4. Hydrogen bonds are represented with dotted lines. Compounds 1, 2, and 4 have a distorted $\mathrm{CsCl}$ type structure. (B) Representation of the $\mathrm{Cu}\left(\mathrm{H}_{2} \mathrm{O}\right)_{5}\left[\left(\mathrm{VOF}_{4}\right) \mathrm{H}_{2} \mathrm{O}\right]$ polar building unit in the structure of $\mathbf{3}$. Hydrogen bonds are represented by dotted lines.

bond-network effects. The electronic effect of the PJT distortion causes an out-of-center displacement of the vanadyl cation toward the oxide. ${ }^{62}$ The coordination of copper to the oxide ligand places a less negative charge on the oxide ligand which results in a slight repulsion of the oxide ligand away from the vanadyl cation. The electronic and bond-network effects result in a vanadyl bond of $1.6059(8) \AA$. The copper cation is coordinated by five water molecules and the oxygen $\mathrm{O} 8$ of the 
Table 1. Crystallographic Information of $\mathrm{MVOF}_{4}\left(\mathrm{H}_{2} \mathrm{O}\right)_{7}$

\begin{tabular}{|c|c|c|c|c|}
\hline & $\mathrm{M}^{\mathrm{II}}=\mathrm{Co}$ & $\mathrm{M}^{\mathrm{II}}=\mathrm{Ni}$ & $\mathrm{M}^{\mathrm{II}}=\mathrm{Cu}$ & $\mathrm{M}^{\mathrm{II}}=\mathrm{Zn}$ \\
\hline compd & 1 & 2 & 3 & 4 \\
\hline crystal system & triclinic & triclinic & orthorhombic & triclinic \\
\hline space group & $P \overline{1}$ & $P \overline{1}$ & $P_{n a 2}$ & $P \overline{1}$ \\
\hline$a(\AA)$ & $6.4784(3)$ & $6.4359(3)$ & $15.632(5)$ & $6.4670(2)$ \\
\hline$b(\AA)$ & $10.9958(4)$ & $10.8948(4)$ & $8.220(5)$ & $10.9809(3)$ \\
\hline$c(\AA)$ & $14.0108(5)$ & $13.9323(6)$ & $7.366(5)$ & $13.9850(4)$ \\
\hline$\alpha(\operatorname{deg})$ & $88.3476(14)$ & $88.238(2)$ & 90 & $88.3500(1)$ \\
\hline$\beta(\operatorname{deg})$ & $88.2253(14)$ & $88.161(2)$ & 90 & $88.2106(1)$ \\
\hline$\gamma(\operatorname{deg})$ & $79.8519(14)$ & $80.212(2)$ & 90 & $79.9730(1)$ \\
\hline$V(\AA)$ & $981.70(7)$ & $961.87(7)$ & $946.5(9)$ & $977.21(5)$ \\
\hline$Z$ & 4 & 4 & 4 & 4 \\
\hline$N_{\text {ref }}$ & 5761 & 7431 & 2806 & 8185 \\
\hline ind reflns $>2 \sigma$ & 5173 & 5959 & 2754 & 6937 \\
\hline$\rho_{\text {calc }}\left(\mathrm{g} / \mathrm{cm}^{3}\right)$ & 2.219 & 2.263 & 2.334 & 2.280 \\
\hline$R_{1}[I>2 \sigma(I)]$ & 0.022 & 0.023 & 0.015 & 0.028 \\
\hline$w R_{2}[I>2 \sigma(I)]$ & 0.064 & 0.057 & 0.040 & 0.062 \\
\hline GooF & 1.05 & 0.96 & 1.07 & 1.05 \\
\hline Flack parameter & & & $0.021(6)$ & \\
\hline
\end{tabular}

Table 2. BVS Calculations for $\mathrm{M}^{\mathrm{II}}$ and $\mathrm{V}^{\mathrm{IV}}$ Ions of Compounds 1-4 (VU) ${ }^{a}$

$\begin{array}{ccccc} & \mathbf{1} & \mathbf{2} & \mathbf{3} & \mathbf{4} \\ \text { M1 } & 2.119 & 2.094 & 2.141 & 2.185 \\ \text { M2 } & 2.104 & 2.087 & & 2.170 \\ \text { M3 } & 2.093 & 2.010 & & 2.188 \\ \text { M4 } & 1.993 & 2.106 & & 2.191 \\ \text { V1 } & 3.952 & 3.929 & 3.953 & 3.996 \\ \text { V2 } & 3.978 & 3.967 & & 3.982\end{array}$

${ }^{a} \mathrm{VU}=$ valence unit.

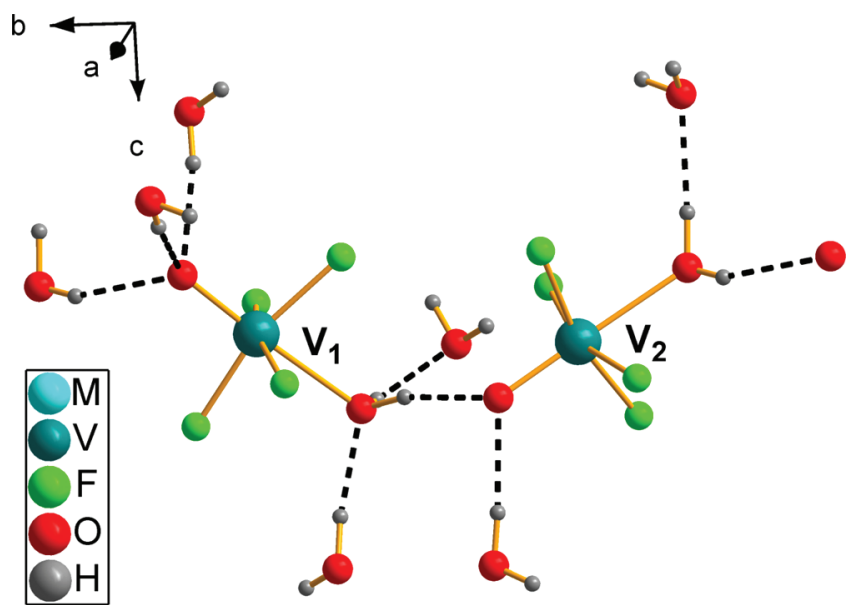

Figure 2. Diagram of hydrogen bonds to the oxygen ligands of the V1 and V2 complexes of the CS heterotypes 1, 2, and 4. Hydrogen bonds are shown in dotted lines; the $\mathrm{OD} \mathrm{BBUs}$ are isolated octahedra connected to the bond-network solely through hydrogen bonds.

vanadyl bond. The FOJT distortion of $\mathrm{Cu}$ II causes the $\mathrm{Cu}-\mathrm{O} 8$ and the corresponding trans $\mathrm{Cu}-\mathrm{O} 4$ bonds to lengthen (2.3315(18) $\AA$ and 2.3800(18) $\AA$, respectively); the four equatorial $\mathrm{H}_{2} \mathrm{O}-\mathrm{Cu}$ distances are between 1.9548(15) $\AA$ and 1.9805(17) A. Each unit is bound to eight adjacent BBUs via inter-BBU hydrogen bonds. The hydrogen-bond geometry

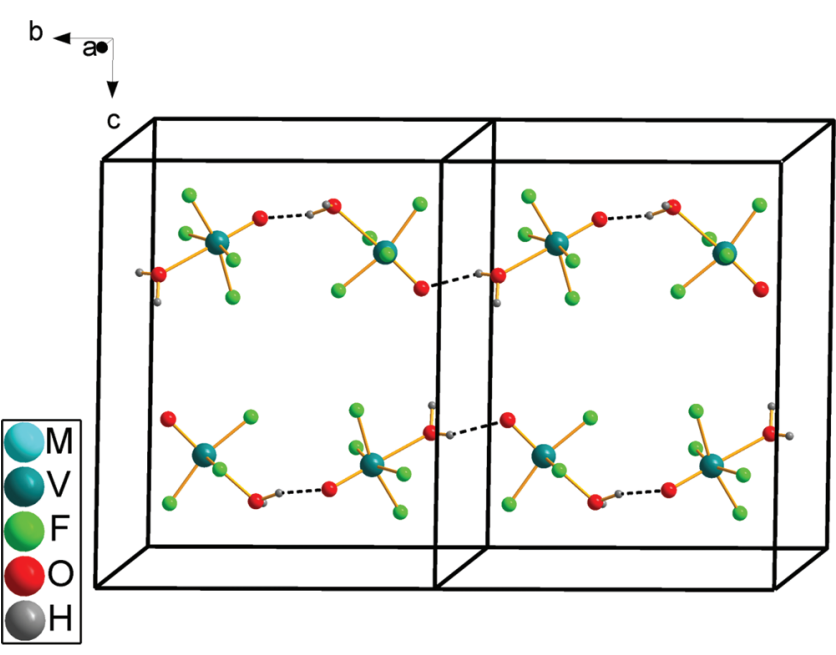

Figure 3. Illustration of the cancellation of dipole moments of $\left[\mathrm{VOF}_{4}\left(\mathrm{H}_{2} \mathrm{O}\right)\right]^{2-}$ for the CS heterotypes; LTMCs have been omitted for clarity. The dipole moment induced by each individual VC is canceled by the symmetry-equivalent $\mathrm{VC}$ generated by the inversion operation. The VCs are oriented in pseudochains in which the hydrogen atoms of the water moiety of one $\mathrm{VC}$ are hydrogen bonding with the oxide ligand of another VC.

parameters of compound 3 are provided in the Supporting Information, Table S15.

Although the $\Lambda$-shaped $\mathrm{BBU} \mathrm{CuVOF}_{4}\left(\mathrm{H}_{2} \mathrm{O}\right)_{6}$ has six water molecules coordinated to metals, the molar formula is $\mathrm{CuVOF}_{4}\left(\mathrm{H}_{2} \mathrm{O}\right)_{7}$, owing to an uncoordinated water molecule within the crystal lattice. Therefore, a more accurate description for the compound is $\mathrm{CuVOF}_{4}\left(\mathrm{H}_{2} \mathrm{O}\right)_{6} \cdot \mathrm{H}_{2} \mathrm{O}$. This water molecule acts as "bridging molecule" with formation of hydrogen bonds; the dipole moment of the water molecule is partially aligned along the polar axis of the crystal and contributes to the crystal's nonlinear responses. Figure 4 shows that the water molecule of $\mathrm{O} 1$ is coordinated via hydrogen bonds to a water molecule of $\mathrm{Cu}^{\mathrm{II}}$ and a fluoride ligand of $\mathrm{V}^{\mathrm{IV}}$; an additional intra-BBU hydrogen bond connects the water molecule identified by $\mathrm{O} 5$ to ligand F3. 


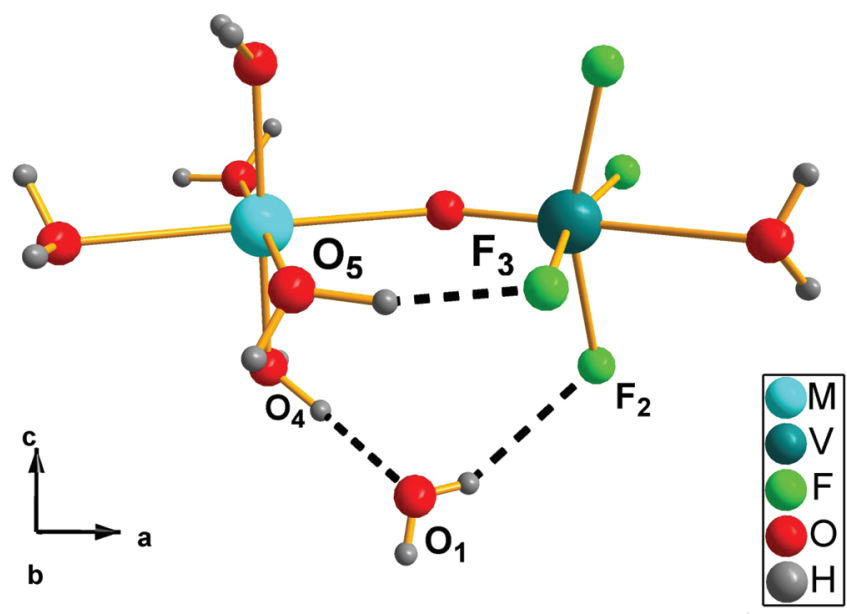

Figure 4. The inter-BBU hydrogen bond of compound 3 and the hydrogen bonds of the BBU that form with the water located in the lattice of the crystal structure. The hydrogen bonds contribute to the formation of the $\Lambda$ shape of compound 3 .

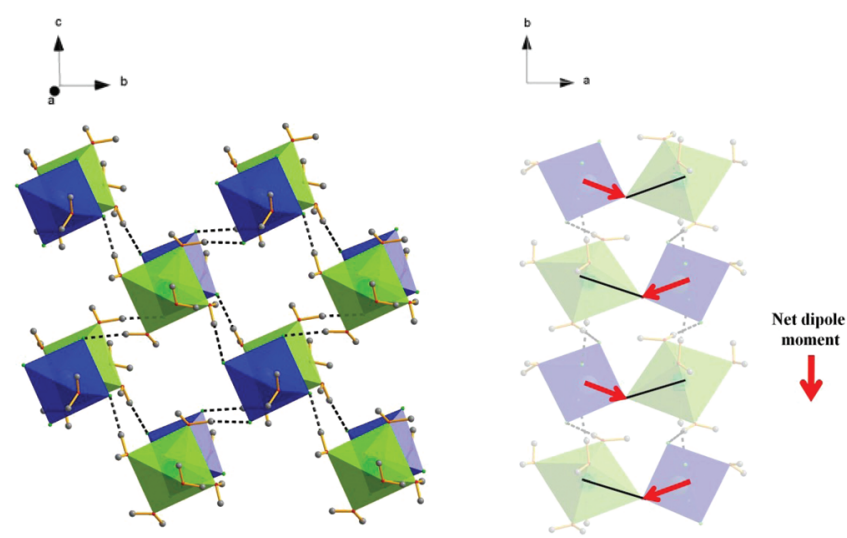

Figure 5. Packing of $\mathrm{CuVOF}_{4}\left(\mathrm{H}_{2} \mathrm{O}\right)_{6}$ units of compound 3 and representation of the net dipole moment in one layer of BBUs by hydrogen bonds of $\mathrm{CuVOF}_{4}\left(\mathrm{H}_{2} \mathrm{O}\right)_{6} \cdot \mathrm{H}_{2} \mathrm{O}$. Hydrogen bonds are represented in dotted lines.

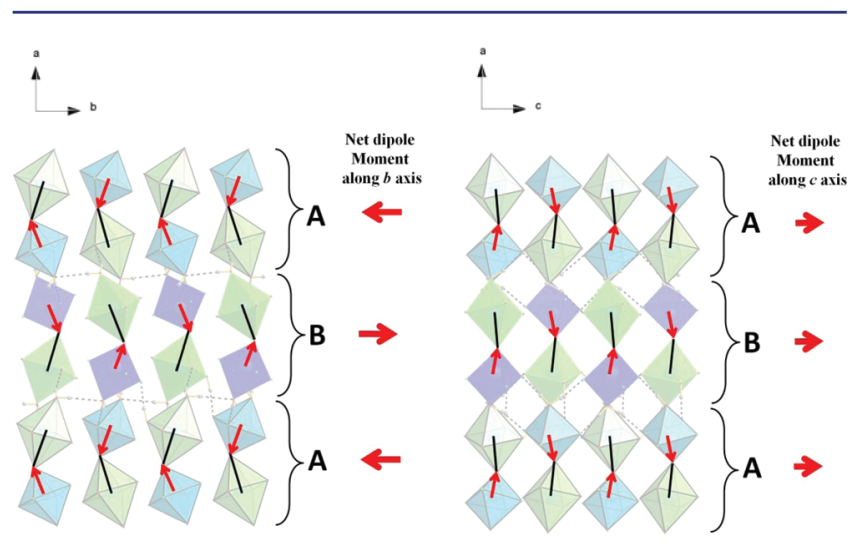

Figure 6. Representation of stacking $A B A B$ of $\mathrm{CuVOF}_{4}\left(\mathrm{H}_{2} \mathrm{O}\right)_{6} \cdot \mathrm{H}_{2} \mathrm{O}$ layers of compound 3 with interlayer hydrogen bonds represented in dotted lines and view of the net dipole orientation along the $b$ and $c$ axes. The hydrogen bonds between $\Lambda$-shaped BBUs within layers have been omitted for clarity. The dipole moment of the $\left[\left(\mathrm{VOF}_{4}\right) \mathrm{H}_{2} \mathrm{O}\right]^{2-}$ is shown with a red arrow.

The $\Lambda$-shaped BBUs stack into pseudolayered units that are aligned in parallel and slightly antiparallel configurations-one such pseudolayer is shown in Figure 5; Figure 6 shows these layers align in an A-B-A pattern as described by the $P n a 2_{1}$ space group. We describe these as "pseudo layers", as they exist with discrete water molecules and $\mathrm{BBUs}$ of $\mathrm{CuVOF}_{4}\left(\mathrm{H}_{2} \mathrm{O}\right)_{6}$ that hydrogen bond to form layered-structures without strong covalent or ionic bonds between BBUs.

Spectroscopic Descriptions. Nonlinear Optical Measurements Indicate a Phase-Matchable SHG Response of Compound 3 on the Order of $\alpha-\mathrm{SiO}_{2}$. A high SHG efficiency can be achieved by a complete dipole alignment within a structure. ${ }^{6}$ The directions of the ETMCs' polar distortions are affected by bond networks and can lead to the cancellation of the overall polar moment of the material. Compound 3 exhibits SHG efficiency on the order of $\alpha-\mathrm{SiO}_{2}$. The SHG response is likely lessened by absorption of $512 \mathrm{~nm}$ light by compound 3, as observed in the UV-vis spectra (see Supporting Information, Figure S3). Phase matching curves of SHG intensity versus particle size are shown in the Supporting Information (Figure S1). The low SHG intensity (relative to $\mathrm{LiNbO}_{3}$ ) is attributable to the cancellation of the dipole moment contributions along the $a$ and $b$ axes. The additive dipoles along the polar $c$ axis allow a weak bulk polarity.

IR Measurements and Bond Lengths Reveal That a Decrease of Oxide Contacts to the Bond Network Causes an Increase of the Vanadyl Bond Strength. The vanadyl oxide of $\mathrm{CuVOF}_{4}\left(\mathrm{H}_{2} \mathrm{O}\right)_{7}$ makes two contacts to the bond network: a covalent bond to vanadium and a covalent bond to copper. Conversely, as shown in Figure 2, the oxide ligand of V1 of the CS heterotypes makes one covalent bond and three hydrogen bonds. The oxide ligand of V2 makes one covalent bond and two hydrogen bonds. This decrease in bond contacts of the oxide ligand to the extended network increases the vanadyl bond strength; the same trend has been observed by our group with $\mathrm{Nb}=\mathrm{O}$ bonds. ${ }^{23}$ To examine these bonds, IR measurements and BVS calculations were performed. Table 3 shows

Table 3. IR Stretching Frequencies, Bond Lengths, and BVS Calculations of the $\mathrm{V}=\mathrm{O}$ Bond in Compounds $1-4$

\begin{tabular}{lllll} 
& \multicolumn{1}{c}{$\mathbf{1}$} & \multicolumn{1}{c}{$\mathbf{2}$} & \multicolumn{1}{c}{3} & \multicolumn{1}{c}{4} \\
$\mathrm{~V}=\mathrm{O} \gamma_{\text {asym }}\left(\mathrm{cm}^{-1}\right)$ & 949.6 & 949.2 & 965.3 & 949.6 \\
$\mathrm{~V}=\mathrm{O} \gamma_{\text {sym }}\left(\mathrm{cm}^{-1}\right)$ & 964.0 & 962.4 & 973.8 & 964.4 \\
$\mathrm{~V}_{1}=\mathrm{O}$ bond & $1.6496(10)$ & $1.6628(9)$ & $1.6069(8)$ & $1.6488(8)$ \\
$\begin{array}{c}\text { length }(\AA) \\
\mathrm{V}_{2}=\mathrm{O} \text { bond }\end{array}$ & $1.6286(10)$ & $1.6377(8)$ & & $1.6310(8)$ \\
length $(\AA)$ & & & & \\
$\mathrm{s}_{\mathrm{V} 1=\mathrm{O}(\mathrm{VU})}$ & 1.438 & 1.439 & 1.614 & 1.441 \\
$\mathrm{~s}_{\mathrm{V} 2=\mathrm{O}}(\mathrm{VU})$ & 1.522 & 1.485 & & 1.512 \\
\hline
\end{tabular}

symmetric and antisymmetric stretching frequencies $(\mathrm{V}=\mathrm{O}$ $\gamma_{\text {sym }}$ and $\mathrm{V}=\mathrm{O} \gamma_{\text {asym }}$, respectively), bond lengths, and BVS sums $\left(S_{i, j}\right)$ for the $\mathrm{V}=\mathrm{O}$ bond for compounds 1-4; the spectra are shown in the Supporting Information (Figure S7). Peak positions were found by fits to Gaussian functions (see Supporting Information, eq S8). For compounds 1, 2, and 4, the individual IR stretches of $\mathrm{V}_{1}=\mathrm{O}$ and $\mathrm{V}_{2}=\mathrm{O}$ could not be resolved; this is likely due to close overlap of the bands. Instead, averages of the IR peaks of these stretches are reported. A shift of the X-H stretches to the $2700-3500 \mathrm{~cm}^{-1}$ region is observed for compound 3 , owing to the different environments of water molecules of compound 3 than its heterotypes. 
Table 4. Magnetic Characteristics of Compounds 1-4

\begin{tabular}{|c|c|c|c|c|}
\hline & 1 & 2 & 3 & 4 \\
\hline TIP (emu/mol) & $1.41 \times 10^{-3}$ & $4.45 \times 10^{-3}$ & $2.20 \times 10^{-4}$ & $1.34 \times 10^{-3}$ \\
\hline$\theta(\mathrm{K})$ & -5.3084 & -0.1659 & -10.64 & 0.2454 \\
\hline no. of unpaired electrons $\left(\mathrm{mol}^{-1}\right)$ & 4 & 3 & 2 & 1 \\
\hline$\mu_{\text {eff }}$ (bohr magnetons) & 5.5 & 3.66 & 2.79 & 1.77 \\
\hline$\mu_{\text {eff theoretical }}{ }^{a}$ (bohr magnetons) & $5.01-5.48$ & $3.38-3.82$ & $2.46-2.80$ & 1.73 \\
\hline
\end{tabular}

${ }^{a}$ See the Supporting Information for theoretical calculation of the effective magnetic moment.

Magnetic Measurements Confirm the Oxidation States for $M^{\prime \prime}$ and $V^{\prime V}$. The magnetic susceptibility measurements showed Curie-Weiss paramagnetic behavior for compounds 1, 2, and 4; compound 3 exhibited antiferromagnetic behavior owing to $\mathrm{Cu}^{\mathrm{II}}$ and $\mathrm{V}^{\mathrm{IV}}$ coupling through the bridging oxide. Compounds $\mathbf{1}, \mathbf{2}$, and 4 are magnetically dilute, and no interaction was observed between the magnetic centers. The compounds have magnetic moments that correspond with their oxidation state $(\mathrm{s})$ of $\mathrm{M}^{\mathrm{II}}$ and $\mathrm{V}^{\mathrm{IV}}$ and $\mathrm{a} \mathrm{d}^{7}, \mathrm{~d}^{8}$, and $\mathrm{d}^{9}$ electronic configuration for $\mathrm{Co}^{\mathrm{II}}, \mathrm{Ni}^{\mathrm{II}}$, and $\mathrm{Cu}^{\mathrm{II}}$, respectively. Curvature was seen in the plots of $1 / \chi$ versus temperature, so a temperatureindependent paramagnetism term was included to fit the data (see Table 4 and the Supporting Information, Figure S6). This phenomenon is common for transition metals and results from low-lying, empty orbitals that arise from splitting of the partially occupied valence shells. ${ }^{62,63}$

Impedance Measurements Show Compound 3 Exhibits Piezoelectric Behavior. Compound 3 exhibits piezoelectric resonance; frequency dependent measurements were performed to rule out the possibilities of the material acting as an electret or ferroelectret; these data are shown in the

Table 5. Room Temperature Resonance Frequencies and $K_{\text {eff }}$ for Two Crystals of Compound 3

\begin{tabular}{lll} 
& \multicolumn{1}{c}{$\mathbf{1}$} & \multicolumn{1}{c}{$\mathbf{2}$} \\
$f_{\mathrm{s}}(\mathrm{Hz})$ & 513467 & 418963 \\
$f_{\mathrm{p}}(\mathrm{Hz})$ & 514357 & 420775 \\
$K_{\text {eff }}$ & 0.059 & 0.093 \\
\hline
\end{tabular}

Supporting Information (S2a). The $K_{\text {eff }}$ was calculated with eq 1 , and the results are listed in Table 5 . The different $K_{\text {eff }}$ values for the two crystals are attributable to different crystal orientations. These values are similar to those of AT cut quartz crystals with $K_{26}=0.088 .{ }^{64}$ A commercial piezoelectric EC65 (ITT Corporation, Salt Lake City, UT, USA) with similar size and geometry was also measured, and $K_{\text {eff }}$ was determined to be 0.44. A high $K_{\text {eff }}$ is desired for power handling, but specific applications do not require a high $K$ value.

\section{DISCUSSION}

The $\Lambda$-shaped BBUs Formation Is Caused by the First Order Jahn-Teller Distortion of Cu". For all compounds 1-4, the VCs and LTMCs exhibit different nucleophilicities of their ligands: the protons of the LTMC are electrophilic, and the fluoride ligands of $\left[\left(\mathrm{VOF}_{4}\right) \mathrm{H}_{2} \mathrm{O}\right]^{2-}$ are nucleophilic, while the oxide ligands are poorly nucleophilic. The vanadyl bond strength is due to significant $\pi$-bonding between vanadium and oxygen. This $\pi$-bonding causes the oxide ligands to have poor nucleophilicity. ${ }^{19,21}$ The vanadyl bond strength is determined by two factors: (i) $\pi$-bonding of the oxide ligand to the early transition metal and (ii) bonding of the oxide ligand to the extended bond network. The magnitude of (i) and (ii) can be quantified with bond-valence calculations. ${ }^{53-56}$ Increase of factor (i) leads to a decrease of factor (ii) and vice versa, owing to valence considerations. Owing to the vanadium cation's strong electrophilicity within compounds 1-4, two structures compete to minimize factor (ii): the NCS Pna $2_{1}$ structure and the CS $P \overline{1}$ structure. The CS structure allows the vanadyl oxide to bond to the hydrogen bond network while the NCS structure eliminates hydrogen bonds to the vanadyl oxide with coordination of the VC to the LTMC.

The valence contributions between fluoride ligands and the extended hydrogen-bond-network range from 0.352 valence units (VU) to $0.548 \mathrm{VU}$. These contributions are equivalent for compounds 1-4, but there are different valence contributions between the oxide ligands and the extended structures of the

Table 6. BVS Calculations for the Bonds of $\left[\mathrm{VOF}_{4}\right]^{2-}$ to the Extended Structure in Compounds 1-4 (VU)

$\begin{array}{llcccc} & & \mathbf{1} & \mathbf{2} & \mathbf{3} & \mathbf{4} \\ \mathrm{V} 1 & \sum \mathrm{s}(\mathrm{F} 1-\mathrm{H}) & 0.373 & 0.386 & 0.446 & 0.363 \\ & \sum \mathrm{s}(\mathrm{F} 2-\mathrm{H}) & 0.442 & 0.441 & 0.481 & 0.510 \\ & \sum \mathrm{s}(\mathrm{F} 3-\mathrm{H}) & 0.427 & 0.441 & 0.515 & 0.415 \\ & \sum \mathrm{s}(\mathrm{F} 4-\mathrm{H}) & 0.447 & 0.440 & 0.454 & 0.548 \\ & \sum \mathrm{s}(\mathrm{O} 16-\mathrm{H}) & 0.292 & 0.286 & & 0.258 \\ \mathrm{~V} 2 & \sum \mathrm{s}(\mathrm{O} 8-\mathrm{Cu}) & & & 0.151 & \\ & \sum \mathrm{s}(\mathrm{F} 5-\mathrm{H}) & 0.391 & 0.418 & & 0.356 \\ & \sum \mathrm{s}(\mathrm{F} 6-\mathrm{H}) & 0.474 & 0.478 & & 0.487 \\ & \sum \mathrm{s}(\mathrm{F} 7-\mathrm{H}) & 0.384 & 0.408 & & 0.352 \\ & \sum \mathrm{s}(\mathrm{F} 8-\mathrm{H}) & 0.452 & 0.442 & & 0.447 \\ & \sum \mathrm{s}(\mathrm{O} 15-\mathrm{H}) & 0.255 & 0.269 & & 0.279 \\ & & & & & \end{array}$

NCS compound 3 and the CS heterotypes 1, 2, and 4. For compound 3, Table 6 shows that while the valence of the copper-oxide bond is $0.15 \mathrm{VU}$, the valence between the oxide ligands and the extended hydrogen-bond network in the CS heterotypes (compounds 1, 2, and 4) ranges from $0.255 \mathrm{VU}$ to 0.292 VU. The position of the hydrogen atoms may be slightly inaccurate, owing to the difficulty of observation of light atoms with X-ray diffraction, but the large difference in valence from the hydrogen bond network is more significant than deviations of the hydrogen atom positions. The oxide ligands of the VC in compound 3 do not extensively bond to the extended structure as compared to the oxide ligands of the CS heterotypes. This is due to poor nucleophilicity of the oxide ligand, ${ }^{19}$ but this weak nucleophilicity is sufficient to bind to a FOJT distorted $\mathrm{Cu}^{\mathrm{II}}$ cation.

Figure 7 shows that compound 3 is more stable in the NCS configuration; if the bonds of the vanadyl to the LTMCs of the 


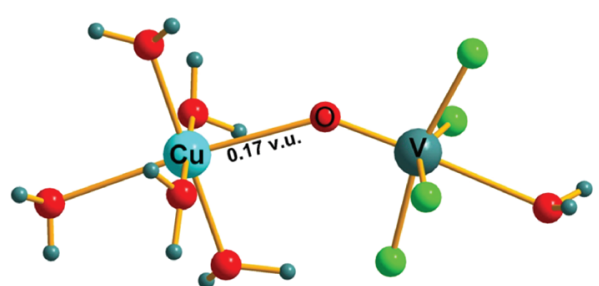

$\mathrm{CuVOF}_{4}\left(\mathrm{H}_{2} \mathrm{O}\right)_{6}$ Bimetallic BBU

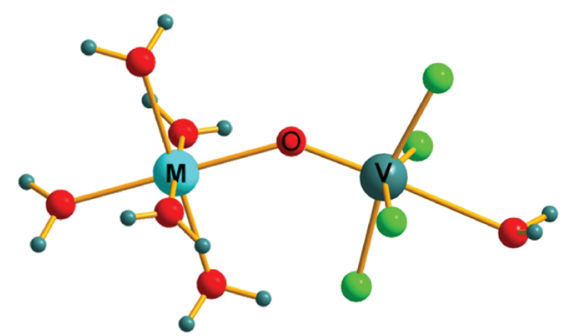

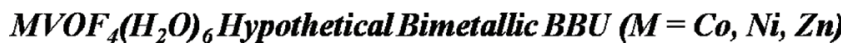

Figure 7. Calculations of the valences between the late transition metals and oxide ligands in the $\mathrm{CuVOF}_{4}\left(\mathrm{H}_{2} \mathrm{O}\right)_{6} . \Lambda$-shaped BBUs and $\operatorname{MVOF}_{4}\left(\mathrm{H}_{2} \mathrm{O}\right)_{6}$ hypothetical $\Lambda$-shaped BBUs. The calculated valences between the late transition metals and oxide ligands are 0.308, 0.323, and $0.347 \mathrm{VU}$ for $\mathrm{Ni}^{\mathrm{II}}, \mathrm{Co}^{\mathrm{II}}$, or $\mathrm{Zn}^{\mathrm{II}}$, respectively.

CS heterotypes were similar to the bonds within the NCS compound 3 , a significant valence increase between the oxide ligand and the extended structure would occur: 0.308, 0.323, and $0.347 \mathrm{VU}$ for $\mathrm{Ni}^{\mathrm{II}}, \mathrm{Co}^{\mathrm{II}}$, and $\mathrm{Zn}^{\mathrm{II}}$, respectively (valences calculated with the longest bond distance $\mathrm{M}-\mathrm{OH}_{2}$ of the CS structure), versus the smaller values shown in Table 6. This is a conservative estimate: if $\mathrm{Ni}^{\mathrm{II}}, \mathrm{Co}^{\mathrm{II}}$, or $\mathrm{Zn}^{\mathrm{II}}$ were to bind to an oxide, the bond distance would be shorter than the observed bond distance to a water molecule and the bond valence contribution would be even greater. Therefore, the CS heterotypes do not have sufficiently low $\mathrm{M}-\mathrm{O}$ bond energy to form $\Lambda$-shaped BBUs and to crystallize in the NCS configuration.

The late transition metal $\mathrm{Cu}^{\mathrm{II}}$ has a FOJT distortion that allows the long $\mathrm{Cu}-\mathrm{O}$ bond to contribute weakly to the BVS of the oxide and allows stronger $\pi$-bonding within the $\mathrm{V}=\mathrm{O}$ bond. Conversely, the $\mathrm{CS}$ heterotypes contain $\mathrm{Co}^{\mathrm{II}}, \mathrm{Ni}^{\mathrm{II}}$, or $\mathrm{Zn}^{\mathrm{II}}$, which do not have strong FOJT distortions and, consequently, compounds 1,2 , and 4 form monomeric BBUs. These monomeric ETMCs form multiple hydrogen bonds to the oxide ligand, which decreases the $\mathrm{V}=\mathrm{O}$ bond strength. This is confirmed by the shift of the FTIR V=O stretches of compound 3 toward higher energy, decreased $\mathrm{V}=$ $\mathrm{O}$ bond lengths, and greater $\mathrm{V}=\mathrm{O}$ valences (see Table 3 ).

The $\mathrm{Cu}-\mathrm{O}=\mathrm{V}$ moiety has been previously observed in the compound $\mathrm{Cu}\left(\mathrm{H}_{2} \mathrm{O}\right)(\mathrm{OH}) \mathrm{VO}\left(\mathrm{VO}_{4}\right)$. The geometries of the bimetallic units of this compound and compound 3 are similar: the bond angles of $\mathrm{Cu}-\mathrm{O}=\mathrm{V}$ in compound 3 and $\mathrm{Cu}\left(\mathrm{H}_{2} \mathrm{O}\right)(\mathrm{OH}) \mathrm{VO}\left(\mathrm{VO}_{4}\right)$ are $142.88(5)^{\circ}$ and $131.5(2)^{\circ}$, respectively. ${ }^{65}$ The compound is CS for reasons that will be described. This hydroxido compound has both distorted $\mathrm{V}^{\mathrm{V}}$ tetrahedra and $\mathrm{V}^{\mathrm{IV}}$ octahedra; the valence contributions of the $\mathrm{V}^{\mathrm{IV}}$ octahedra's equatorial oxide ligands from the extended structure range from 1.286 to $1.725 \mathrm{VU}$. The vanadyl oxide only makes one contact to the extend network: to the $\mathrm{Cu}^{\mathrm{II}}$ cation. The $\mathrm{Cu}-\mathrm{O}$ has a bond length of 2.359 (4) $\AA$ for a valence of $0.159 \mathrm{VU}$; the valences of the equatorial bonds to the extended structure are greater than the copper-oxide bond.
This corroborates that the weak nucleophilicity of the vanadyl bond is still sufficiently able to bind to an axial oxide ligand of a FOJT distorted $\mathrm{Cu}$.

Coordination of Water in a Position trans to the Oxide Ligand of the VC Prevents Centrosymmetric BBUs. Previous OD oxide/oxyfluoride vanadium bimetallic BBUs include $\left[\mathrm{V}_{2} \mathrm{O}_{2} \mathrm{~F}_{8}\right]^{4-},\left[\mathrm{V}_{2} \mathrm{O}_{2} \mathrm{~F}_{6}\left(\mathrm{H}_{2} \mathrm{O}\right)_{2}\right]^{2-},\left[\mathrm{V}_{2} \mathrm{O}_{2} \mathrm{~F}_{7}\right]^{3-}$, $\left[\mathrm{V}_{2} \mathrm{O}_{7}\right]^{4-}$, and $\left[\left(\mathrm{VO}_{3}\right)_{2}\right]^{2-}$.66-68 These dimers have fluoride ligands located trans to the oxide ligand of distorted octahedra and are very nucleophilic. ${ }^{19,22,24,69}$ Similarly, the dimer $\left[\mathrm{V}_{2} \mathrm{O}_{8}(\mathrm{OH})_{2}\right]^{2-}$ of the hydroxido $\mathrm{Cu}\left(\mathrm{H}_{2} \mathrm{O}\right)(\mathrm{OH}) \mathrm{VO}$ $\left(\mathrm{VO}_{4}\right)$ has nucleophilic hydroxide ions located trans to the oxide ligand. ${ }^{65}$ These BBUs contain crystallographically equivalent ETMCs that distort away from each other to generate a zero net dipole and an inversion center within the $\mathrm{BBU}$; a CS material results from these CS BBUs. Cationcation repulsions between ETMCs within these BBUs direct the distortions into antiparallel manners that cause a zero netdipole moment. ${ }^{29}$ To create NCS structures, these BBUs should be avoided. Another divanadium BBU $\left[\mathrm{V}_{2} \mathrm{O}_{2} \mathrm{~F}_{8^{-}}\right.$ $\left.\left(\mathrm{H}_{2} \mathrm{O}\right)\right]^{5-}$ is an interesting case: it contains $\left[\mathrm{V}^{\mathrm{V}} \mathrm{OF}_{5}\right]^{2-}$ and $\left[\mathrm{V}^{\mathrm{IV}} \mathrm{OF}_{4}\left(\mathrm{H}_{2} \mathrm{O}\right)\right]^{2-}$ octahedra that are bridged by a fluoride ligand. ${ }^{70}$ This fluoride is located trans to the oxide ligand of the $\mathrm{V}^{\mathrm{V}}$ octahedron but is located on an equatorial position of the $\mathrm{V}^{\mathrm{IV}}$ octahedron; the water molecule within $\left[\mathrm{V}^{\mathrm{IV}} \mathrm{OF}_{4}\right.$ $\left.\left(\mathrm{H}_{2} \mathrm{O}\right)\right]^{2-}$ does not act as a bridging ligand. Replacing the fluoride ligand with a ligand such as water - that has its valence fulfilled by hydrogen atoms-prevents coordination to the ligand trans to the oxide ligand of the $\left[\mathrm{V}^{\mathrm{IV}} \mathrm{OF}_{4}\left(\mathrm{H}_{2} \mathrm{O}\right)\right]^{2-}$ anion. The coordination of water to the $\left[\mathrm{V}^{\mathrm{IV}} \mathrm{OF}_{4}\left(\mathrm{H}_{2} \mathrm{O}\right)\right]^{2-} \mathrm{VC}$ creates a $\Lambda$-shaped BBU that does not have an inversion center but packs within a CS framework; the presence of an NCS dimer is not the sole criterion to create an NCS material.

The $\Lambda$-Shape of the BBU Allows for the BBUs To Pack with a Net Polar Moment. The intra-BBU interactions of compound 3 induce the $\mathrm{BBU}$ into a $\Lambda$-shape. The $[\mathrm{Cu}-$ $\left.\left(\mathrm{H}_{2} \mathrm{O}\right)_{5}\right]^{2+}$ and $\left[\operatorname{VOF}_{4}\left(\mathrm{H}_{2} \mathrm{O}\right)\right]^{2-}$ ions combine and form a $\Lambda$ shaped $\mathrm{BBU}$ owing to the creation of an hydrogen bond between a water molecule of the cation and one fluoride ligand of the anion (Figure $1 \mathrm{~b}$ ). Specifically, the hydrogen bond H9F3 (1.694(19) $\AA$ ) induces the BBU to distort to the $\Lambda$-shaped $\mathrm{Cu}\left(\mathrm{H}_{2} \mathrm{O}\right)_{5}\left[\left(\mathrm{VOF}_{4}\right) \mathrm{H}_{2} \mathrm{O}\right]$. The $\Lambda$-shaped $\mathrm{BBU}$ causes the structure to pack into an NCS structure, as evidenced by piezoelectric and SHG measurements (see the Supporting Information). Hydrogen bonds have been previously observed to allow arrangement of polar moments into configurations that have a net dipole moment in materials. ${ }^{10,12}$

The $\Lambda$ shape is important for the design of BBUs without an inversion center and for packing of the BBUs into an NCS environment. Chemists have tailored organic and hybrid materials to $\Lambda$-shaped BBUs, as they have a high probability of packing into NCS crystals. ${ }^{8,30,33,71-74}$ For $\Lambda$-shaped organic molecules, such as $N, N^{\prime}$-bis(4-ethoxycarbonylphenyl)methaneiamin, minimization of intermolecular hydrogen bonds causes a preference for stacking of $\Lambda$-shaped units and synthesis of an NCS crystal structure. ${ }^{30}$ Similarly, our group has previously reported that minimizing contacts to the oxide ligand can lead to NCS, polar structures. ${ }^{23}$ This is demonstrated with the $\Lambda$-shaped BBUs of the NCS compound 3there are only two contacts to the oxide of the polar $\mathrm{VC}$, but the CS heterotypes have four bond contacts to the oxide ligand. Minimal contacts to the oxide ligand could be accomplished with the $\Lambda$-shaped BBU synthesis with ETMCs. 
In the case of compound 3, the non-ETMC fulfills the valence of the oxide and effectively "caps" the oxide to prevent further bonding to this ligand

Compound 3's NCS property is due to its polarity and the specific architecture that induces partial polar alignment. In the structure of compound 3, the BBUs pack so as to maximize the hydrogen bonding within the structure. The net dipole vectors are partially aligned along the $c$ axis, owing to rotation of the $\Lambda$ shaped-BBU layers after two successive layers (Figure 6). This layered structure with a slight alignment along the $c$ axis is also seen in crystallized, racemic mixtures of the amino acid DLalanine. As with compound 3, DL-alanine belongs to the $P n a 2_{1}$ space group. The crystal structure of DL-alanine is unusual: although it is a racemic mixture, it crystallizes in a polar crystal structure. ${ }^{51,75,76}$ The crystal structure of the zwiterrionic DLalanine consists of each unique enantiomer on one of two specific planes, connected to the extended structure hydrogen bonds. The crystal structure has been successfully predicted with computational methods. Cooper et al. found that the use of quantum-mechanically optimized structures of the molecules D- and L-alanine was not suitable for prediction of the ultimate crystal structures; rather, by limiting specific torsional angles to those of similar structures contained in the Cambridge Structural Database (CSD), the correct crystal structure was computationally determined. ${ }^{77}$ Such analyses of inorganic BBUs could allow predictions of NCS crystal structures.

The $\Lambda$-shaped BBU stacking direction is not necessarily perpendicular to their individual polar moments; however, the $\Lambda$-shaped BBUs are geometrically difficult to stack into a CS structure. At the very least, partial alignment of the polar moments of the $\Lambda$-shaped BBUs is likely to result. If we consider, shown in Figure 8, four scenarios of two geometrically different BBUs within a $2 \mathrm{D}$ unit cell, (a) linear BBUs and $(b-d)$ $\Lambda$-shaped BBUs, the rotation of BBUs in scenario a with respect to their intermetallic axis would not change the net polarity. In scenarios $b-d$, however, rotation of the BBUs with respect to their intermetallic axes can modify the net polarity. Rotation in the manner of scenario $b$ has occurred in $\Lambda$-shaped BBUs of $\left[\mathrm{Nb}_{2} \mathrm{O}_{3} \mathrm{~F}_{8}\right]^{4-}$ when the BBUs were templated by $\mathrm{CS}$, organic ethylenediaminium cations located on inversion centers. ${ }^{78}$ Figure 8 shows that, so long as the rotation of one $\mathrm{BBU}$ is not equal and opposite to the rotation of another BBU (scenario b), $\Lambda$-shaped BBUs will necessarily result in a net polar moment in a bulk material (scenarios $\mathrm{c}$ and $\mathrm{d}$ ). Even for simplified 2D shapes, the difficulties of generating polarity within a bulk material are varied and rich in complexities and deserve further inquiry by the inorganic chemistry community.

Future work to increase the dipole moment alignment of $\Lambda$ shaped BBUs would increase the NLO responses of the materials. As described in organic chemistry, this could be accomplished by maximizing the steric properties of $\Lambda$-shaped BBUs with use of larger ions, organic ligands, and/or placement of the $\Lambda$-shaped BBUs in bulkier 1D chains, 2D layers, or 3D architectures with maintenance of the NCS property. ${ }^{30}$ Future work to increase the dipole moment alignment of $\Lambda$-shaped BBUs would increase the NLO and piezoelectric response of materials. Additionally, we and others have described the use of hard and soft cations to specifically coordinate to fluoride or oxide ligands, respectively. ${ }^{13,79-83}$ The appropriate use of a soft cation, such as a late transition metal (in this case $\mathrm{Cu}^{\mathrm{II}}$ ), may be able to coordinate solely to the oxide ligand without bonding to fluoride ligands, to result in "capped" oxide ligands. These

\section{a)}

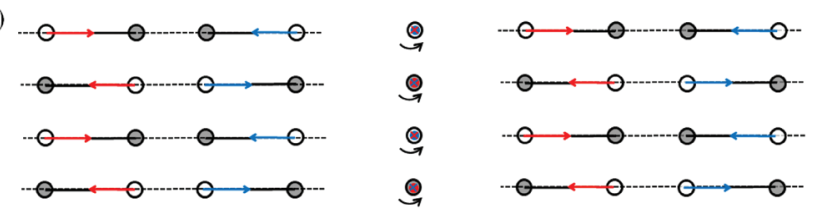

b)
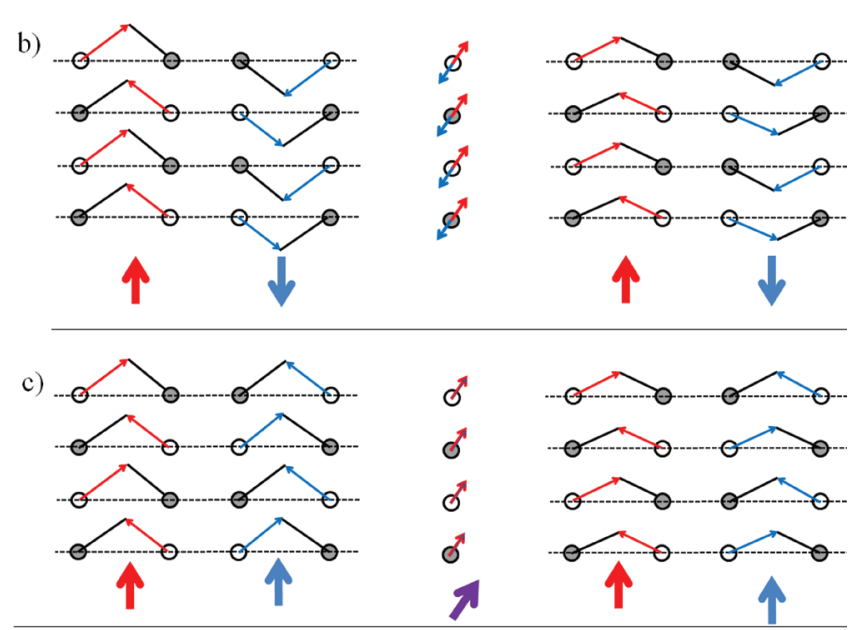

d)
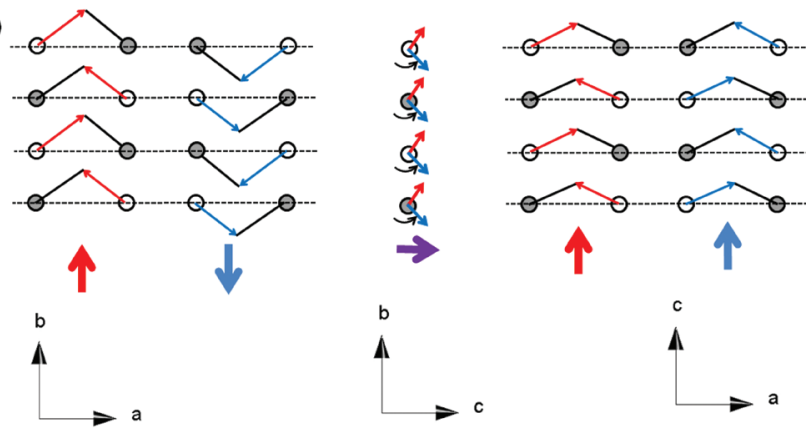

Figure 8. Illustration of dipole moments in various scenarios: (a) canceled after rotation of adjacent linear dimers, (b) canceled owing to opposite orientation of adjacent $\Lambda$-shaped dimers, (c) added owing to similar orientation of adjacent $\Lambda$-shaped BBUs, and (d) added along one axis by rotation of adjacent $\Lambda$-shaped BBUs (observed for the $\mathrm{CuVOF}_{4}\left(\mathrm{H}_{2} \mathrm{O}\right)_{7}$ compound). Red and blue arrows represent the individual polarities of two different groups of $\Lambda$-shaped dimers. Gray and white circles represent metallic centers. The dotted line represents the intermetallic axis.

bimetallic BBUs would then have fewer rotational degrees of freedom as in the case of $\Lambda$-shaped BBUs.

\section{CONCLUSION}

The purely inorganic, polar $\mathrm{CuVOF}_{4}\left(\mathrm{H}_{2} \mathrm{O}\right)_{7}$ and its centrosymmetric heterotypes $\mathrm{MVOF}_{4}\left(\mathrm{H}_{2} \mathrm{O}\right)_{7}\left[\mathrm{M}^{\mathrm{II}}=\mathrm{Co}, \mathrm{Ni}\right.$, and $\left.\mathrm{Zn}\right]$ were synthesized by hydrothermal methods and analytically characterized. Owing to copper's first order Jahn-Teller distortion, the $\left[\mathrm{Cu}\left(\mathrm{H}_{2} \mathrm{O}\right)_{5}\right]^{2+}$ cation and $\left[\left(\mathrm{VOF}_{4}\right) \mathrm{H}_{2} \mathrm{O}\right]^{2-}$ anion connect through an oxide ligand to ultimately create a $\Lambda$-shaped BBU. Similar to organic $\Lambda$-shaped molecules, the $\Lambda$-shaped BBUs $\mathrm{CuVOF}_{4}\left(\mathrm{H}_{2} \mathrm{O}\right)_{6}$ pack into a polar, NCS structure. The $\Lambda$-shape motif can be employed to create polar materials with nonlinear optical responses. As we have demonstrated, $\Lambda$-shape basic-building units crystallize in NCS structures when heterotypes with monomeric BBUs do not. The CS heterotypes illustrate that distorted ETMCs are not the sole criterion for synthesis of NCS structures, nor is the combination of distorted 
ETMCs and LTMCs; rather, attention should be paid to the bond orientation of polar BBUs to their near and next-nearest neighbor(s). To progress from $0 \mathrm{D}$ distorted polyhedra to $3 \mathrm{D}$ polar crystals, inorganic chemists can understand how simple shapes-such as $\Lambda$-shape BBUs-can be synthesized and oriented in the bulk to create polar materials.

\section{ASSOCIATED CONTENT}

\section{S Supporting Information}

Experimental details of diffuse reflectance spectroscopy, powder XRD measurements, impedance spectroscopy, magnetic characterization, EDX spectroscopy, ICP elemental analysis, FTIR spectroscopy, and structure analysis with PLATON; Figures S1-S13 showing a plot of the SHG response of compound 3 as a function of particle size, diffuse reflectance spectra of the compounds, powder XRD of the compounds, EDX spectra of the compounds, the magnetic susceptibility of the compounds as a function of temperature, FTIR spectra of the compounds, suggested unit cells from PLATON for compounds 1, 2, and 4, and hydrogen bonds formed to the VCs and LTMCs for compounds 1, 2, and 4; Tables S1-S19 containing ICP-AES results, FTIR spectra fitting parameters, refinement parameters of structures 1,2 , and 4 in a unit cell suggested by PLATON, and atomic parameters of the compounds; and CIF data of compounds 1-4. This material is available free of charge via the Internet at http://pubs.acs.org.

\section{AUTHOR INFORMATION}

\section{Corresponding Author}

krp@northwestern.edu

\section{Author Contributions}

${ }^{\dagger}$ These two authors contributed equally to this work and are co-first authors.

\section{ACKNOWLEDGMENTS}

This work was supported by funding from the National Science Foundation (Solid State Chemistry Award Nos. DMR1005827). We would like to thank Sylvie Malo and Sylvie Hebert (CRISMAT) for performing magnetic measurements on compounds 1-4. P.S.H. and J.Y. thank the Robert A. Welch Foundation (Grant E-1457) for support. Powder XRD patterns were obtained on instruments supported by the MRSEC program of the National Science Foundation (DMR-0520513) at the Materials Research Center of Northwestern University. EDX spectra were obtained at the Electron Probe Instrumentation Center at Northwestern University. Diffuse-reflectance spectra were obtained at the Keck Biophysics Facility at Northwestern University, which is supported by grants from the W.M. Keck Foundation, Northwestern University, the NIH, the Rice Foundation, and the Robert H. Lurie Comprehensive Cancer Center. Single crystal X-ray data and analytical measurements were acquired at Northwestern University's Integrated Molecular Structure Education and Research Center (IMSERC). Instruments and software at IMSERC were purchased with grants from NSF-NSEC, NSF-MRSEC, the Keck Foundation, the state of Illinois, and Northwestern University. We additionally thank Amy Sarjeant and Charlotte Stern for invaluable assistance and discussions regarding the crystal structures. We thank Matthew McCrory (Northwestern University Academic \& Research Technologies) for creation of the cover art.

\section{REFERENCES}

(1) Lippman, G. Ann. Chim. Phys. 1881, 24, 145.

(2) Valasek, J. Phys. Rev. 1920, 15, 537.

(3) Franken, P. A.; Hill, A. E.; Peters, C. W.; Weinreich, G. Phys. Rev. Lett. 1961, 7, 118.

(4) Aoyama, Y.; Endo, K.; Anzai, T.; Yamaguchi, Y.; Sawaki, T.; Kobayashi, K.; Kanehisa, N.; Hashimoto, H.; Kai, Y.; Masuda, H. J. Am. Chem. Soc. 1996, 118, 5562.

(5) Nangia, A.; Desiraju, G. R. Acta Crystallogr., Sect. A 1998, 54, 934.

(6) Ye, N.; Chen, Q.; Wu, B.; Chen, C. J. Appl. Phys. 1998, 84, 555.

(7) Thalladi, V. R.; Boese, R.; Brasselet, S.; Ledoux, I.; Zyss, J.; Jetti, R. K. R.; Desiraju, G. R. Chem. Commun. (Cambridge, U. K.) 1999 1639.

(8) Evans, O. R; Lin, W. Acc. Chem. Res. 2002, 35, 511.

(9) Maggard, P. A.; Nault, T. S.; Stern, C. L.; Poeppelmeier, K. R. J. Solid State Chem. 2003, 175, 27.

(10) Stephens, N. F.; Buck, M.; Lightfoot, P. J. Mater. Chem. 2005, 15, 4298.

(11) Ok, K. M.; Chi, E. O.; Halasyamani, P. S. Chem. Soc. Rev. 2006, 35,710 .

(12) Xue, D.; Zhang, S. Chem. Phys. Lett. 1999, 301, 449.

(13) Marvel, M. R.; Lesage, J.; Baek, J.; Halasyamani, P. S.; Stern, C. L.; Poeppelmeier, K. R. J. Am. Chem. Soc. 2007, 129, 13963.

(14) Chen, C. T. Acta Phys. Sin. 1976, 25, 146.

(15) Chen, C. T. Acta Phys. Sin. 1977, 26, 124.

(16) Chen, C. T. Acta Phys. Sin. 1977, 26, 468.

(17) Chen, C. T. Acta Phys. Sin. 1979, 22, 756.

(18) Becker, P. Adv. Mater. (Weinheim, Ger.) 1998, 10, 979.

(19) Welk, M. E.; Norquist, A. J.; Stern, C. L.; Poeppelmeier, K. R. Inorg. Chem. 2000, 39, 3946.

(20) Maggard, P. A.; Stern, C. L.; Poeppelmeier, K. R. J. Am. Chem. Soc. 2001, 123, 7742.

(21) Welk, M. E.; Norquist, A. J.; Arnold, F. P.; Stern, C. L.; Poeppelmeier, K. R. Inorg. Chem. 2002, 41, 5119.

(22) Izumi, H. K.; Kirsch, J. E.; Stern, C. L.; Poeppelmeier, K. R. Inorg. Chem. 2005, 44, 884.

(23) Marvel, M. R.; Lesage, J.; Baek, J.; Halasyamani, P. S.; Stern, C. L.; Poeppelmeier, K. R. J. Am. Chem. Soc. 2007, 129, 13963.

(24) Kirsch, J. E.; Izumi, H. K.; Stern, C. L.; Poeppelmeier, K. R. Inorg. Chem. 2005, 44, 4586.

(25) Adil, K.; Leblanc, M.; Maisonneuve, V.; Lightfoot, P. Dalton Trans. 2010, 39, 5983.

(26) Halasyamani, P.; Willis, M. J.; Stern, C. L.; Poeppelmeier, K. R. Inorg. Chim. Acta 1995, 240, 109.

(27) Pevec, A.; Tekavec, M.; Demsar, A. Polyhedron 2011, 30, 549.

(28) Rouse, J.; Redrup, K. V.; Kotsapa, E.; Weller, M. T. Chem. Commun. (Cambridge, U. K.) 2009, 7209.

(29) Kunz, M.; Brown, I. D. J. Solid State Chem. 1995, 115, 395.

(30) Yamamoto, H.; Katogi, S. Appl. Phys. Lett. 1992, 60, 935.

(31) Tao, X. T.; Watanabe, T.; Shimoda, S.; Zou, D. C.; Sato, H.; Miyata, S. Chem. Mater. 1994, 6, 1961.

(32) Tao, X. T.; Watanabe, T.; Zou, D. C.; Shimoda, S.; Usui, H.; Sato, H.; Miyata, S. J. Polym. Sci., Part B: Polym. Phys. 1995, 33, 2205.

(33) Chang, P.-H.; Chen, J.-Y.; Tsai, H.-C.; Hsiue, G.-H. J. Polym. Sci., Part A: Polym. Chem. 2009, 47, 4937.

(34) Pearson, R. G. Proc. Natl. Acad. Sci. U. S. A. 1975, 72, 2104.

(35) Chen, C. T. Sci. Sin. 1978, 22, 756.

(36) Bertolini, J. C. J. Emerg. Med. 1991, 10, 163.

(37) Peters, D.; Miethchen, R. J. Fluorine Chem. 1996, 79, 161.

(38) Segal, E. B. Chem. Health Saf. 2000, 7, 18.

(39) Harrison, W. T. A.; Nenoff, T. M.; Gier, T. E.; Stucky, G. D. Inorg. Chem. 1993, 32, 2437.

(40) Foster, H. B. Vanadium oxide catalyst. Office, U. S. P., Eds. National Aniline \& Chemical Company, Inc.: United States of America, 1933; Vol. 2,180,353, p 1.

(41) Cotton, F. A.; Wilkinson, G.; Murillo, C. A.; Bochmann, M. Advanced Inorganic Chemistry, 6th ed.; John Wiley \& Sons, Inc.: New York, NY, 1999. 
(42) 7.23A ed.; Bruker Analytical X-ray Instruments, Inc.: Madison, WI, 2005.

(43) Sheldrick, G. M.; Bruker Analytical X-Ray Instruments, Inc.: Madison, WI, 1997.

(44) Altomare, A.; Burla, M. C.; Camalli, M.; Cascarano, G. L.; Giacovazzo, C.; Guagliardi, A.; Moliterni, A. G. G.; Polidori, G.; Spagna, R. J. Appl. Crystallogr. 1999, 32, 115.

(45) Farrugia, L. J. J. Appl. Crystallogr. 1999, 32, 837.

(46) Sheldrick, G. Acta Crystallogr., Sect. A 2008, 64, 112.

(47) Spek, A. L. Utrecht University: Utrecht, The Netherlands, 2001.

(48) Hooft, R. W. W.; Straver, L. H.; Spek, A. L. J. Appl. Crystallogr.

2008, 41, 96.

(49) Mabbs, F. E.; Machin, D. J. Magnetism and Transition Metal Complexes; Dover Publications, Inc.: Mineola, NY, 1973.

(50) An Introduction to the Theory of Piezoelectricity; Yang, J. S., Ed.; Springer: New York, 2005.

(51) Rieckhoff, K. E.; Peticolas, W. L. Science 1965, 147, 610.

(52) Kurtz, S. K.; Perry, T. T. J. Appl. Phys. 1968, 39, 3798.

(53) Brown, I. D.; Altermatt, D. Acta Crystallogr., Sect. B 1985, 41, 244.

(54) Brown, I. D. Phys. Chem. Miner. 1987, 15, 30.

(55) Brese, N. E.; O’Keeffe, M. Acta Crystallogr., Sect. B 1991, 47, 192.

(56) Adams, S.; Moretzki, O.; Canadell, E. Solid State Ionics 2004, 168, 281.

(57) An Introduction to Hydrogen Bonding; Jeffrey, G. A., Ed.; Oxford University Press: Oxford, 1997.

(58) Pauling, L. Z. Kristallogr. 1930, 72.

(59) Ray, S.; Zalkin, A.; Templeton, D. H. Acta Crystallogr., Sect. B 1973, 29, 2741.

(60) Hoskins, B.; Linden, A. Aust. J. Chem. 1987, 40, 565.

(61) Pervov, V. S.; Leonidov, V. Y.; Klyuev, L. I.; Muravina, A. G. Dokl. Akad. Nauk SSSR 1974, 214, 1088.

(62) Ballhausen, C. J.; Gray, H. B. Inorg. Chem. 1962, 1, 111.

(63) Fowler, P. W.; Steiner, E. J. Chem. Soc., Faraday Trans. 1993, 89, 1915.

(64) Metizer, A. H.; Tiersten, H. F.; Warner, A. W.; Berlincourt, D.; Couqin, G. A.; Welsh, F. S. IEEE: New York, 1988.

(65) Trombe, J.-C.; Rozier, P.; Galy, J. Acta Crystallogr., Sect. C 2003, 59 , i50.

(66) Aldous, D. W.; Goff, R. J.; Attfield, J. P.; Lightfoot, P. Inorg. Chem. 2007, 46, 1277.

(67) Aldous, D. W.; Stephens, N. F.; Lightfoot, P. Dalton Trans. 2007, 2271.

(68) Mahenthirarajah, T.; Li, Y.; Lightfoot, P. Inorg. Chem. 2008, 47, 9097.

(69) Welk, M. E.; Stern, C. L.; Poeppelmeier, K. R.; Norquist, A. J. Cryst. Growth Des. 2007, 7, 956.

(70) Hilbers, M.; Leimkuhler, M.; Mattes, R. Z. Z. Naturforsch. 1989, $44 b, 383$.

(71) Kuo, W.-J.; Hsiue, G.-H.; Jeng, R.-J. Macromol. Rapid Commun. 2001, 22, 601.

(72) Kawamata, J.; Akiba, M.; Inagaki, Y. Chem. Lett. 2001, 30, 1026.

(73) Das, M.; Trivedi, R.; Khattak, B. Q.; Ramshankar, P.; Sen, P.; Dolui, S. K.; Sen, P. K. J. Nonlinear Opt. Phys. Mater. 2008, 17, 329.

(74) Chang, P.-H.; Tsai, H.-C.; Chen, Y.-R.; Chen, J.-Y.; Hsiue, G.-H. Langmuir 2008, 24, 11921.

(75) Levy, H. A.; Corey, R. B. J. Am. Chem. Soc. 1941, 63, 2095.

(76) Donohue, J. J. Am. Chem. Soc. 1950, 72, 949.

(77) Cooper, T. G.; Jones, W.; Motherwell, W. D. S.; Day, G. M. CrystEngComm 2007, 9, 595.

(78) Stephens, N. F.; Lightfoot, P. Acta Crystallogr., Sect. C 2005, C61, m344.

(79) Guillory, P. C. R.; Kirsch, J. E.; Izumi, H. K.; Stern, C. L.; Poeppelmeier, K. R. Cryst. Growth Des. 2005, 6, 382.

(80) Norquist, A. J.; Heier, K. R.; Stern, C. L.; Poeppelmeier, K. R. Inorg. Chem. 1998, 38, 6495.

(81) Aldous, D. W.; Lightfoot, P. Solid State Sci. 2009, 11, 315.
(82) Marvel, M. R.; Pinlac, R. A. F.; Lesage, J.; Stern, C. L.; Poeppelmeier, K. R. Z. Anorg. Allg. Chem. 2009, 635, 869.

(83) Pinlac, R. A. F.; Stern, C. L.; Poeppelmeier, K. R. Crystals 2011, $1,3$. 